University of Wollongong

Research Online

Faculty of Engineering and Information

Faculty of Engineering and Information

Sciences - Papers: Part A

Sciences

$1-1-2015$

\title{
Analysis of an activated sludge model in which dead biomass is recycled into slowly biodegradable particulate substrate
}

Asma O. Alharbi

University of Wollongong, aoma093@uowmail.edu.au

Mark lan Nelson

University of Wollongong, mnelson@uow.edu.au

Annette L. Worthy

University of Wollongong, annie@uow.edu.au

Harvinder S. Sidhu

University of New South Wales, h.sidhu@adfa.edu.au

Follow this and additional works at: https://ro.uow.edu.au/eispapers

Part of the Engineering Commons, and the Science and Technology Studies Commons

Research Online is the open access institutional repository for the University of Wollongong. For further information contact the UOW Library: research-pubs@uow.edu.au 


\title{
Analysis of an activated sludge model in which dead biomass is recycled into slowly biodegradable particulate substrate
}

\begin{abstract}
A significant drawback of the activated sludge process is the production of excess 'sludge'; the disposal of which can account for $50-60 \%$ of the running costs of a wastewater treatment plant. We investigate a model for the activated sludge process in which the influent contains a mixture of soluble and slowly biodegradable particulate substrate. Within the bioreactor, the particulate substrate is hydrolyzed to form soluble substrate. In turn, these are used for growth by the biomass. Biomass decay produces slowly biodegradable substrate and non-biodegradable particulates. Steady-state analysis is used to investigate how the amount of sludge formed depends upon the residence time and the use of a settling unit. We show that when the steady-state sludge content is plotted as a function of the residence time that there are three generic response diagrams. The value of the effective recycle parameter determines which type of response diagram is observed. If this parameter is greater than a critical value, then the sludge content is guaranteed to be greater than a target value. The dependence of this critical value upon the chemical oxygen demand in the feed and how the chemical oxygen demand is partitioned between its constitutive components is investigated.

\section{Disciplines}

Engineering | Science and Technology Studies

\section{Publication Details}

Alharbi, A. O. M., Nelson, M. lan., Worthy, A. L. \& Sidhu, H. S. (2015). Analysis of an activated sludge model in which dead biomass is recycled into slowly biodegradable particulate substrate. Asia-Pacific Journal of Chemical Engineering, 10 (4), 580-597.
\end{abstract}




\section{Analysis of an activated sludge model in which dead biomass \\ is recycled into slowly biodegradable particulate substrate}

\begin{tabular}{|r|l|}
\hline Journal: & Asia-Pacific Journal of Chemical Engineering \\
\hline Manuscript ID: & Draft \\
\hline Datey - Manuscript type: & Research Article \\
\hline Complete List of Authors: & $\begin{array}{l}\text { Alharbi, Asma; University of Wollongong, School of Mathematics and } \\
\text { Applied Statistics } \\
\text { Nelson, Mark; University of Wollongon, School of Mathematics and Applied } \\
\text { Statistics } \\
\text { Worthy, Annette; University of Wollongong, School of Mathematics and } \\
\text { Applied Statistics } \\
\text { Sidhu, Harvinder; University of New South Wales at Australian Defence } \\
\text { Force Academy, School of Physical Environmental and Mathematical } \\
\text { Sciences }\end{array}$ \\
\hline Keywords: & $\begin{array}{l}\text { activated sludge, modelling, recycling, settling unit, wastewater, water } \\
\text { treatment }\end{array}$ \\
\hline &
\end{tabular}

SCHOLARONE ${ }^{m}$

Manuscripts 


\title{
Analysis of an activated sludge model in which dead biomass is recycled into slowly biodegradable particulate substrate
}

\author{
A.O.M. Alharbi (1), M.I. Nelson (1)* Annette L. Worthy (1) and H.S. Sidhu (2), \\ (1) School of Mathematics and Applied Statistics, University of Wollongong, \\ Wollongong, NSW 2522 Australia. \\ (2) School of Physical, Environmental and Mathematical Science, UNSW at ADFA, \\ Canberra, ACT 2600, Australia
}

November 15, 2014

\begin{abstract}
The activated sludge process is one of the major processes used in the biological treatment of wastewater. A significant drawback of this process is the production of excess sludge, the disposal of which can account for $50-60 \%$ of the running costs of a plant.

We investigate a model for the activated sludge process in which the influent contains a mixture of soluble and slowly biodegradable particulate substrate. Within the bioreactor the biodegradable particulate substrate is hydrolyzed to form soluble substrate. In turn these are used for growth by the biomass. Biomass decay produces slowly biodegradable substrate in addition to non-biodegradable particulates.

We use steady-state analysis to investigate how the amount of sludge formed depends upon the residence time and the use of a settling unit. We show that when the steady-state sludge content is plotted as a function of the residence time that there are three generic response diagrams, depending upon the value of the effective recycle parameter. We find that if the effective recycle parameter is higher than a critical value then sludge content is guaranteed to be greater than a target value. We investigate how this critical value depends upon the chemical oxygen demand in the feed and how the chemical oxygen demand is partitioned between its constitutive components.
\end{abstract}

Keywords activated sludge; modelling; recycling; settling unit; wastewater; water treatment.

\section{Introduction}

Historically waste products such as agricultural and industrial wastewaters and sewage were placed on fields, where natural environmental processes broke them down. In 1913 Ardern and Lockett at Davyhulme (Manch-

*Corresponding author. Phone: (61)-2-4221-4400. Fax: (61)-2-4221-4845. Email: nelsonm@member.ams.org. 
ester, UK) discovered the activated sludge process, which has since become the most common process for treating sewage and industrial wastewater using air [17, page 4]. This process essentially uses two units, an aerated biological reactor, where the pollutants are degraded by bacteria, and a settling unit (or clarifier) where the activated sludge settles into the bottom of the unit. Activated sludge is recycled from the bottom of the clarifier to the biological reactor.

The first models for bioreactors were developed in the 1960s $[7,8,16]$. These models assume that there is one limiting substrate, one limiting microorganism and one rate-limiting biochemical reaction. Although biomass death is included in the model none of the decay products are recycled into the substrate pool. This is the 'basic model' for the activated sludge process. More detailed models have subsequently been devised, such as the Activated Sludge models developed by the IWA $[6,9,15]$. These models have been extended to model processes in membrane bioreactors $[4,14]$. Recent developments in the mathematical modeling of the activated sludge process are reviewed in $[5,11]$. However, the 'basic model' remains attractive because it is easy to calibrate.

Chung and Neethling [3] extended the basic model in two ways. Firstly, they introduced a slowly biodegradable substrate component which is hydrolysed to produce small soluble organic materials. (These are the limiting substrate of the basic model). Secondly, they allowed a fraction of the dead biomass to be recycled back into the soluble substrate pool. They calibrated their model against experimental steady-state data and used it to estimate the fraction of the total volatile suspended solids that was due to biomass. They investigated how this fraction varied as a function of the sludge age.

The model of Chung and Neethling has the advantage over the IWA models that it is amenable to mathematical analysis, rather than relying on numerical simulations. In earlier work we analysed the Chung and Neethling model [1]. In particular we studied how the 'sludge response diagram', which shows the steady-state sludge content as a function of the residence time, changes as the effective recycle parameter, which characterizes the operation of the recycle unit, is varied.

Here we change one of the assumptions in the Chung and Neethling model. Namely, instead of a fraction of the dead biomass being recycled into the pool of soluble substrate we assume that it is instead recycled into the pool of particulate substrate. Were appropriate we discuss where the results of these models agree and differ.

We find the steady-state solutions and determine their stability as a function of process parameters. These are used to calculate the steady-state chemical oxygen demand and the steady-state volatile suspended solids as a function of the residence time. We use the steady-state results to investigate the circumstances under which it is possible to operate the reactor at, or below, a target value for the volatile suspended solids.

\section{Biochemistry}

In this section we discuss the biochemistry of the model. The three biological processes occurring in the model are shown schematically in figure 1 . These processes are described below. 
1. Biodegradable particulate substrate $\left(X_{s}\right)$ is hydrolysed to give soluble substrate $(S)$.

$$
X_{s} \stackrel{k_{h}}{\rightarrow} S
$$

2. Soluble organic materials $(S)$ are used as substrates for energy and growth by the biomass $\left(X_{b}\right)$.

$$
S \stackrel{\mu(s)}{\longrightarrow} \alpha_{g} X_{b}
$$

where $\alpha_{g}$ is the yield factor for the growth of biomass.

3. The death of biomass adds to the pool of biodegradable particulate substrate $\left(X_{S}\right)$ and non-biodegradable particulates $\left(X_{p}\right)$.

$$
X_{b} \stackrel{k_{d}}{\longrightarrow} f_{p} X_{p}+\left(1-f_{p}\right) X_{s}
$$

where $f_{p}$ is the fraction of dead biomass converted to non-biodegradable particulate $\left(0 \leq f_{p} \leq 1\right)$.

The sequence of biological processes (1) - (3) converts slowly biodegradable substrate through biomass back to slowly biodegradable particulate substrate. In addition to the variables identified above $\left(S, X_{b}, X_{p}\right.$ and $\left.X_{S}\right)$ we also allow for the possibility that the feed contains particulate inert material $\left(X_{i}\right)$.

\section{$3 \quad$ Equations}

In this section we write down the model equations for the concentration of microorganisms, non-biodegradable particulates, slowly biodegradable particulates, particulate inert material, and soluble substrate within a wellstirred, well-aerated, bioreactor.

\subsection{The dimensional model}

The model equations in the bioreactor are given by.

The rate of change of soluble substrate

$$
V \frac{\mathrm{d} S}{\mathrm{~d} t}=F\left(S_{0}-S\right)+V k_{h} X_{s}-\frac{V X_{b} \mu(S)}{\alpha_{g}} .
$$

The rate of change of biomass

$$
V \frac{\mathrm{d} X_{b}}{\mathrm{~d} t}=F\left(X_{b, 0}-X_{b}\right)+R F(C-1) X_{b}+V \mu(S) X_{b}-V k_{d} X_{b}
$$

The rate of change of slowly biodegradable particulates.

$$
V \frac{\mathrm{d} X_{s}}{\mathrm{~d} t}=F\left(X_{s, 0}-X_{s}\right)+R F(C-1) X_{s}+V\left(1-f_{p}\right) k_{d} X_{b}-V k_{h} X_{s} .
$$


The rate of change of non-biodegradable particulates

$$
V \frac{\mathrm{d} X_{p}}{\mathrm{~d} t}=F\left(X_{p, 0}-X_{p}\right)+R F(C-1) X_{p}+V f_{p} k_{d} X_{b} .
$$

The rate of change of particulate inert material

$$
V \frac{\mathrm{d} X_{i}}{\mathrm{~d} t}=F\left(X_{i, 0}-X_{i}\right)+R F(C-1) X_{i} .
$$

The specific growth rate is

$$
\mu(S)=\frac{\mu_{m} S}{K_{s}+S} .
$$

The residence time is

$$
\tau=\frac{V}{F}
$$

The chemical demand oxygen (COD)

$$
\mathrm{COD}=S+X_{s}
$$

Total Volatile Suspended Solids (VSS)

$$
\mathrm{VSS}=X_{b}+X_{s}+X_{p}+X_{i}
$$

All parameters are defined in appendix A.

For a specific wastewater, a given biological community, and a particular set of environmental conditions, the parameters $K_{s}, k_{d}, k_{h}, \alpha_{g}$ and $\mu_{m}$ are fixed. The parameters that can be varied are $S_{0}, X_{j, 0}(j=b, p, i, s)$, and $\tau$. The operation of the settling unit is characterised by the parameters $C$ and $R$. In practice, a target value for the VSS is set. We take the target value to be $\operatorname{VSS}_{t}=12000 \mathrm{mg} l^{-1}$ [18].

\subsection{The dimensionless model}

By introducing the dimensionless parameters and variables defined in appendix A the dimensional model, equations (4)-(8), can be written in the dimensionless form.

$$
\begin{aligned}
\frac{\mathrm{d} S^{*}}{\mathrm{~d} t^{*}} & =\frac{1}{\tau^{*}}\left(S_{0}^{*}-S^{*}\right)+\alpha_{g} k_{h}^{*} X_{s}^{*}-\frac{S^{*} X_{b}^{*}}{1+S^{*}}, \\
\frac{\mathrm{d} X_{b}^{*}}{\mathrm{~d} t^{*}} & =\frac{1}{\tau^{*}}\left(X_{b, 0}^{*}-X_{b}^{*}\right)+\frac{R^{*}}{\tau^{*}} X_{b}^{*}+\frac{X_{b}^{*} S^{*}}{1+S^{*}}-k_{d}^{*} X_{b}^{*}, \\
\frac{\mathrm{d} X_{s}^{*}}{\mathrm{~d} t^{*}} & =\frac{1}{\tau^{*}}\left(X_{s, 0}^{*}-X_{s}^{*}\right)+\frac{R^{*}}{\tau^{*}} X_{s}^{*}+\left(1-f_{p}\right) k_{d}^{*} X_{b}^{*}-k_{h}^{*} X_{s}^{*}, \\
\frac{\mathrm{d} X_{p}^{*}}{\mathrm{~d} t^{*}} & =\frac{1}{\tau^{*}}\left(X_{p, 0}^{*}-X_{p}^{*}\right)+\frac{R^{*}}{\tau^{*}} X_{p}^{*}+f_{p} k_{d}^{*} X_{b}^{*}, \\
\frac{\mathrm{d} X_{i}^{*}}{\mathrm{~d} t^{*}} & =\frac{1}{\tau^{*}}\left(X_{i, 0}^{*}-X_{i}^{*}\right)+\frac{R^{*}}{\tau^{*}} X_{i}^{*} .
\end{aligned}
$$


The dimensionless chemical oxygen demand

$$
\mathrm{COD}^{*}=S^{*}+\alpha_{g} X_{s}^{*}
$$

Dimensionless total volatile suspended solids

$$
\mathrm{VSS}_{t}^{*}=X_{b}^{*}+X_{s}^{*}+X_{p}^{*}+X_{i}^{*}
$$

Dimensionless total volatile suspended solids in the feed

$$
\mathrm{VSS}_{\mathrm{in}}^{*}=X_{b, 0}^{*}+X_{s, 0}^{*}+X_{p, 0}^{*}+X_{i, 0}^{*} .
$$

From now on we assume that the growth medium fed into the bioreactor is sterile, i.e. there are no microorganisms in the influent $\left(X_{b, 0}=X_{b, 0}^{*}=0\right)$. It is important to note for what follow that the effective recycle parameter is bounded by: $0 \leq R^{*} \leq 1$.

Note that the target value for volatile suspended solids is

$$
\mathrm{VSS}_{\text {target }}^{*}=\frac{\mathrm{VSS}_{\text {target }}}{\alpha_{g} K_{s}}=\frac{12000}{\alpha_{g} K_{s}}=3.4510 .
$$

\subsection{Model simplification}

The differential equations (16) \& (17) are not coupled to the other equations. In fact equation (17) is a linear first-order autonomous differential equation which is readily integrated to obtain the time dependent solution. Equation (16) is a linear first-order non-autonomous differential equation, in which time appears implicitly through the variable $X_{b}^{*}\left(t^{*}\right)$. It is possible to write down a formal solution to this differential equation using an integrating factor. As we are interested in the long-time behaviour of the system we put both of the variables $X_{i}^{*}$ and $X_{p}^{*}$ equal to their steady-state values. In the limit of large time the system $(13)-(17)$ reduces to

$$
\begin{aligned}
\frac{\mathrm{d} S^{*}}{\mathrm{~d} t^{*}} & =\frac{1}{\tau^{*}}\left(S_{0}^{*}-S^{*}\right)+\alpha_{g} k_{h}^{*} X_{s}^{*}-\frac{S^{*} X_{b}^{*}}{1+S^{*}}, \\
\frac{\mathrm{d} X_{b}^{*}}{\mathrm{~d} t^{*}} & =\frac{1}{\tau^{*}}\left(X_{b, 0}^{*}-X_{b}^{*}\right)+\frac{R^{*}}{\tau^{*}} X_{b}^{*}+\frac{X_{b}^{*} S^{*}}{1+S^{*}}-k_{d}^{*} X_{b}^{*}, \\
\frac{\mathrm{d} X_{s}^{*}}{\mathrm{~d} t^{*}} & =\frac{1}{\tau^{*}}\left(X_{s, 0}^{*}-X_{s}^{*}\right)+\frac{R^{*}}{\tau^{*}} X_{s}^{*}+\left(1-f_{p}\right) k_{d}^{*} X_{b}^{*}-k_{h}^{*} X_{s}^{*}, \\
X_{i}^{*} & =\frac{X_{i, 0}^{*}}{1-R^{*}}, \\
X_{p}^{*} & =\frac{X_{p, 0}^{*}}{1-R^{*}}+\frac{f_{p} k_{d}^{*} X_{b}^{*} \tau^{*}}{1-R^{*}} .
\end{aligned}
$$

\section{Results}

In steady-state diagrams we follow the standard convention and indicate stable and unstable solution branches by solid and dotted lines respectively. We use a square to denote a transcritical bifurcation, denoting the highest residence time at which process failure occurs. 


\subsection{Steady-state solution branches}

The steady-state solutions are found by putting the derivative equal to zero in equations (22)-(24) and then solving the resulting system of equations. The steady-state solutions are given by

Washout branch.

$$
\begin{aligned}
S^{*} & =S_{w}^{*}=S_{0}^{*}+\frac{\alpha_{g} k_{h}^{*} X_{s, 0}^{*} \tau^{*}}{1-R^{*}+k_{h}^{*} \tau^{*}}, \\
X_{b}^{*} & =0 \\
X_{s}^{*} & =X_{\mathrm{sw}}^{*}=\frac{X_{s, 0}^{*}}{1-R^{*}+k_{h}^{*} \tau^{*}}, \\
X_{p}^{*} & =X_{\mathrm{pw}}^{*}=\frac{X_{p, 0}^{*}}{1-R^{*}}, \\
X_{i}^{*} & =\frac{X_{i, 0}^{*}}{1-R^{*}}, \\
\mathrm{COD}_{w}^{*} & =S_{0}^{*}+\frac{\left(1+k_{h}^{*} \tau^{*}\right) \alpha_{g} X_{s, 0}^{*}}{1-R^{*}+k_{h}^{*} \tau^{*}}, \\
\mathrm{VSS}_{w}^{*} & =\frac{X_{s, 0}^{*}}{1-R^{*}+k_{h}^{*} \tau^{*}}+\frac{X_{p, 0}^{*}}{1-R^{*}}+\frac{X_{i, 0}^{*}}{1-R^{*}} .
\end{aligned}
$$

The washout branch corresponds to process failure due to removal of all the biomass $\left(X_{b}^{*}=0\right)$. The steady-state expressions for the washout branch are equivalent to the expressions when dead biomass is recirculated into the pool of soluble substrate [1]. This is unsurprising as the biochemistry of the two models are identical when there is no biomass present in the reactor $\left(X_{b}^{*}=0\right)$.

Differentiating equation (27) with respect to the residence time we see that the soluble substrate concentration along the no-washout branch is an increasing function

$$
\frac{\mathrm{d} S_{w}^{*}}{\mathrm{~d} \tau^{*}}=\frac{\alpha_{g} k_{h}^{*} X_{s, 0}^{*}\left(1-R^{*}\right)}{\left(1-R^{*}+k_{h}^{*} \tau^{*}\right)^{2}}>0 .
$$

No-washout branch.

$$
\begin{aligned}
S^{*} & =S_{\mathrm{nw}}^{*}=\frac{1-R^{*}+k_{d}^{*} \tau^{*}}{R^{*}-1+\left(1-k_{d}^{*}\right) \tau^{*}}, \\
X_{\mathrm{bnw}}^{*} & =\frac{\left(a S_{\mathrm{nw}}^{* 2}+b S_{\mathrm{nw}}^{*}+c\right)\left[R^{*}-1+\left(1-k_{d}^{*}\right) \tau^{*}\right]}{\left(a_{1} \tau^{* 2}+b_{1} \tau^{*}+c_{1}\right) \tau^{*}}, \\
X_{s}^{*} & =X_{\mathrm{snw}}^{*}=\frac{X_{s, 0}^{*}+\left(1-f_{p}\right) k_{d}^{*} X_{\mathrm{bnw}} \tau^{*}}{1-R^{*}+k_{h}^{*} \tau^{*}}, \\
X_{p}^{*} & =X_{\mathrm{pnw}}^{*}=\frac{X_{p, 0}^{*}+f_{p} k_{d}^{*} X_{\mathrm{bnw}} \tau^{*}}{1-R^{*}}, \\
X_{i}^{*} & =\frac{X_{i, 0}^{*}}{1-R^{*}}, \\
\mathrm{COD}_{\mathrm{nw}}^{*} & =\frac{1-R^{*}+k_{d}^{*} \tau^{*}}{\left(1-k_{d}^{*}\right) \tau^{*}-1+R^{*}}+\frac{\alpha_{g} X_{s, 0}^{*}+\left(1-f_{p}\right) \alpha_{g} k_{d}^{*} X_{\mathrm{bnw}}^{*} \tau^{*}}{1-R^{*}+k_{h}^{*} \tau^{*}}, \\
\mathrm{VSS}_{\mathrm{nw}}^{*} & =\left[1+\frac{f_{p} k_{d}^{*} \tau^{*}}{1-R^{*}}+\frac{\left(1-f_{p}\right) k_{d}^{*} \tau^{*}}{1-R^{*}+k_{h}^{*} \tau^{*}}\right] X_{\mathrm{b}, \mathrm{NW}}^{*}+\frac{X_{s, 0}^{*}}{1-R^{*}+k_{h}^{*} \tau^{*}}+\frac{X_{p, 0}^{*}}{1-R^{*}}+\frac{X_{i, 0}^{*}}{1-R^{*}} .
\end{aligned}
$$


The coefficients are

$$
\begin{array}{ll}
a=1-R^{*}+k_{h}^{*} \tau^{*} \geq 0, & a_{1}=-\left[1-\left(1-f_{p}\right) \alpha_{g}\right] k_{h}^{*} k_{d}^{*}<0, \\
b=\left(1-R^{*}\right)\left(1-S_{0}^{*}\right)+\left(1-S_{0}^{*}-\alpha_{g} X_{s, 0}^{*}\right) k_{h}^{*} \tau^{*}, & b_{1}=\left(R^{*}-1\right)\left(k_{h}^{*}+k_{d}^{*}\right)<0, \\
c=-\left(1-R^{*}\right) S_{0}^{*}-\left(S_{0}^{*}+\alpha_{g} X_{s, 0}^{*}\right) k_{h}^{*} \tau^{*}<0, & c_{1}=-\left(R^{*}-1\right)^{2} \leq 0 .
\end{array}
$$

It is interesting to observe that the expression for the substrate concentration is identical to that when the dead biomass is recycled into the soluble substrate pool [1]. Indeed they are both identical to the expression in the basic model [12]. However, the expressions for all other equivalent state variables are not identical.

The conditions for the no-washout branch to be physically meaningful are established in Appendix C. When the no-washout branch is not physically meaningful then the only stable steady state is the washout solution. In this circumstances process failure must occur. This case can therefore be ignored.

Differentiating equation (35) with respect to the recycle parameter we obtain

$$
\frac{\mathrm{d} S_{\mathrm{NW}}^{*}}{\mathrm{~d} R^{*}}=\frac{-\tau^{*}}{\left[\left(1-k_{d}^{*}\right) \tau^{*}-1+R^{*}\right]^{2}}<0 .
$$

Hence the substrate concentration is a decreasing function of the effective recycle parameter $\left(R^{*}\right)$.

Differentiating equation (35) with respect to the residence time we obtain

$$
\frac{\mathrm{d} S_{N W}^{*}}{\mathrm{~d} \tau^{*}}=\frac{R^{*}-1}{\left[\left(1-k_{d}^{*}\right) \tau^{*}-1+R^{*}\right]^{2}}
$$

which is a strictly monotonically decreasing function of the residence time, i.e. the lowest effluent concentration is obtained at an infinite residence time. (It follows from the analysis in appendix $\mathrm{C}$ that the no-washout branch is not defined at the vertical asymptote of equation (42).)

For a flow reactor with idealized recycle or an idealized membrane reactor $\left(R^{*}=1\right)$, the substrate concentration is independent of the residence time and is given by

$$
S^{*}\left(R^{*}=1\right)=\frac{k_{d}^{*}}{1-k_{d}^{*}} .
$$

\subsection{Transcritical bifurcation}

By comparing the identities (27)-(33) with the identities (35)-(41) we see that the washout branch and the no-washout branch are identical when

$$
\begin{aligned}
& S_{w}^{*}=S_{\mathrm{nw}}^{*}, \\
& \Rightarrow S_{0}^{*}+\frac{\alpha_{g} k_{h}^{*} X_{s, 0}^{*} \tau^{*}}{1-R^{*}+k_{h}^{*} \tau^{*}}=\frac{1-R^{*}+k_{d}^{*} \tau^{*}}{\left(1-k_{d}^{*}\right) \tau^{*}-1+R^{*}} .
\end{aligned}
$$

This intersection point corresponds to a transcritical bifurcation. After some algebra we find that this is true when the residence time satisfies the quadratic equation $Q\left(\tau^{*}\right)=0$, where

$$
Q\left(\tau^{*}\right)=a_{2} \tau^{2 *}+b_{2} \tau^{*}+c_{2},
$$


and the coefficients are

$$
\begin{aligned}
a_{2} & =\left[\left(S_{0}^{*}+\alpha_{g} X_{s, 0}^{*}\right)-\left(1+S_{0}^{*}+\alpha_{g} X_{s, 0}^{*}\right) k_{d}^{*},\right] k_{h}^{*}, \\
& =\left[\mathrm{COD}_{\mathrm{in}}^{*}-\left(1+\mathrm{COD}_{\mathrm{in}}^{*}\right) k_{d}^{*}\right] k_{h}^{*}, \\
b_{2} & =-\left(1-R^{*}\right)\left[\left(1+S_{0}^{*}\right)\left(k_{h}^{*}+k_{d}^{*}\right)+k_{h}^{*} \alpha_{g} X_{s, 0}^{*}-S_{0}^{*}\right], \\
& =-\left(1-R^{*}\right)\left[k_{h}^{*}\left(1+\mathrm{COD}_{\mathrm{in}}^{*}\right)+k_{d}^{*}-\left(1-k_{d}^{*}\right) S_{0}^{*}\right] \\
c_{2} & =-\left(1-R^{*}\right)^{2}\left(1+S_{0}^{*}\right)<0 .
\end{aligned}
$$

It it useful to note that equations (43)-(46) are identical to equations (76)-(79) in appendix C. It follows from the analysis in appendix $\mathrm{C}$ that that transcritical bifurcation point is physically meaningful only when $a_{2}>0$ and that it is defined by

$$
\tau_{+}^{*}=\left(1-R^{*}\right) \tau_{\mathrm{cr}}^{*}\left(R^{*}=0\right)
$$

where

$$
\begin{aligned}
\tau_{\mathrm{cr}}^{*}\left(R^{*}=0\right) & =\frac{b_{3}+\sqrt{b_{3}^{2}+4 a_{2} c_{3}}}{2 a_{2}}, \\
b_{3} & =\left[k_{h}^{*}\left(1+\mathrm{COD}_{\mathrm{in}}^{*}\right)+k_{d}^{*}-\left(1-k_{d}^{*}\right) S_{0}^{*}\right], \\
c_{3} & =\left(1+S_{0}^{*}\right) .
\end{aligned}
$$

The condition $a_{2} \geq 0$ is

$$
k_{d}^{*} \leq \frac{\mathrm{COD}_{\mathrm{in}}^{*}}{1+\mathrm{COD}_{\mathrm{in}}^{*}}
$$

The critical value of the decay rate, equation (51), only depends upon the value of the chemical oxygen demand in the feed. However, the expression for the critical value of the residence time, equation (48), depends upon how the chemical oxygen demand is partitioned into its components, as shown in the expressions for the coefficients of $b_{3}$ and $c_{3}$. Expressions (48) \& (51). are identical to those in the model where the dead biomass is recycled into the substrate pool [1].

\subsection{Stability of the steady-state solutions}

The Jacobian matrix is given by

$$
J\left(S^{*}, X_{b}^{*}, X_{s}^{*}\right)=\left(\begin{array}{ccc}
-\frac{1}{\tau^{*}}-\frac{X_{b}^{*}}{\left(1+S^{*}\right)^{2}} & -\frac{S^{*}}{1+S^{*}} & \alpha_{g} k_{h}^{*} \\
\frac{X_{b}^{*}}{\left(1+S^{*}\right)^{2}} & \frac{R^{*}-1}{\tau^{*}}+\frac{S^{*}}{1+S^{*}}-k_{d}^{*} & 0 \\
0 & \left(1-f_{p}\right) k_{d}^{*} & \frac{R^{*}-1}{\tau^{*}}-k_{h}^{*}
\end{array}\right) .
$$




\subsubsection{Stability of the washout branch}

The Jacobian matrix evaluated at the washout steady-state solution is given by

$$
J\left(S_{w}^{*}, 0, X_{s w}^{*}\right)=\left(\begin{array}{ccc}
-\frac{1}{\tau^{*}} & -\frac{S_{w}^{*}}{1+S_{w}^{*}} & \alpha_{g} k_{h}^{*} \\
0 & \frac{R^{*}-1}{\tau^{*}}+\frac{S_{w}^{*}}{1+S_{w}^{*}}-k_{d}^{*} & 0 \\
0 & \left(1-f_{p}\right) k_{d}^{*} & \frac{R^{*}-1}{\tau^{*}}-k_{h}^{*}
\end{array}\right) .
$$

The eigenvalues of this matrix are

$$
\begin{aligned}
& \lambda_{1}=-\frac{1}{\tau^{*}}<0, \\
& \lambda_{2}=\frac{\left(1-R^{*}\right)}{\tau^{*}}-k_{h}^{*}<0, \quad\left(\text { recall that } 0 \leq R^{*} \leq 1\right), \\
& \lambda_{3}=\frac{R^{*}-1}{\tau^{*}}+\frac{S_{w}^{*}}{1+S_{w}^{*}}-k_{d}^{*} .
\end{aligned}
$$

The stability of the washout branch depends upon the sign of $\lambda_{3}$.

We now show that there is a critical value $\left(k_{\mathrm{d}, \mathrm{cr}, \infty}^{*}\right)$ such that the washout branch is always stable when $k_{\mathrm{d}, \mathrm{cr}, \infty}^{*}<k_{d}^{*} \leq 1$. The eigenvalue $\lambda_{3}$ will be negative when

$$
k_{d}^{*} \geq k_{\mathrm{d}, \mathrm{cr}}^{*}=\frac{S_{w}^{*}}{1+S_{w}^{*}}=\frac{S_{0}^{*}\left(1-R^{*}\right)+\left(S_{0}^{*}+\alpha_{g} X_{s, 0}^{*}\right) k_{h}^{*} \tau^{*}}{\left(1+S_{0}^{*}\right)\left(1-R^{*}\right)+\left(1+S_{0}^{*}+\alpha_{g} X_{s, 0}^{*}\right) k_{h}^{*} \tau^{*}} .
$$

Note that

$$
\frac{\mathrm{d} k_{\mathrm{d}, \mathrm{cr}}^{*}}{\mathrm{~d} \tau^{*}}=\frac{\alpha_{g} X_{s, 0}^{*} k_{h}^{*}\left(1-R^{*}\right)}{\left[\left(1+S_{0}^{*}\right)\left(1-R^{*}\right)+\left(1+S_{0}^{*}+\alpha_{g} X_{s, 0}^{*}\right) k_{h}^{*} \tau^{*}\right]^{2}} \geq 0 .
$$

Thus $k_{\mathrm{d}, \mathrm{cr}}^{*}$ has a minimum value $S_{0}^{*} /\left(1+S_{0}^{*}\right)$ when $\tau^{*}=0$ and a maximum value $\left(k_{\mathrm{d}, \mathrm{cr}, \infty}^{*}\right)$ when

$$
\begin{aligned}
k_{\mathrm{d}, \mathrm{cr}, \infty}^{*} & =\lim _{\tau^{*} \rightarrow \infty} \frac{S_{0}^{*}\left(1-R^{*}\right)+\left(S_{0}^{*}+\alpha_{g} X_{s, 0}^{*}\right) k_{h}^{*} \tau^{*}}{\left(1+S_{0}^{*}\right)\left(1-R^{*}\right)+\left(1+S_{0}^{*}+\alpha_{g} X_{s, 0}^{*}\right) k_{h}^{*} \tau^{*}}, \\
& =\frac{S_{0}^{*}+\alpha_{g} X_{s, 0}^{*}}{1+S_{0}^{*}+\alpha_{g} X_{s, 0}^{*}} . \\
& =\frac{\mathrm{COD}_{\mathrm{in}}^{*}}{1+\mathrm{COD}_{\mathrm{in}}^{*}} .
\end{aligned}
$$

If $k_{d}^{*} \geq k_{\mathrm{d}, \mathrm{cr}, \infty}^{*}$ then the washout branch is always stable.

We now consider the case $k_{d}^{*}<k_{\mathrm{d}, \mathrm{cr}, \infty}^{*}$ and show that there is a critical value of the residence time, $\tau_{\mathrm{cr}}^{*}$, such that if $\tau^{*}<\tau_{\mathrm{cr}}^{*}$ then the washout solution is locally stable.

After some algebra we find that the eigenvalue $\lambda_{3}$ can be written

$$
\lambda_{3}=\frac{-Q\left(\tau^{*}\right)}{B}
$$

where $Q\left(\tau^{*}\right)$ is defined by equation (43) and the coefficient B is given by

$$
B=-\left(1-R^{*}\right)\left(1+S_{0}^{*}\right) \tau^{*}-\left(1+S_{0}^{*}+\alpha_{g} X_{s, 0}^{*}\right) k_{h}^{*} \tau^{* 2}<0 . \quad\left(\text { Recall that } 0 \leq R^{*} \leq 1\right)
$$


The denominator $B$ is always negative. Hence the problem of establishing $\lambda_{3}<0$ reduces to determining when $-Q\left(\tau^{*}\right)$ is positive, i.e. when the quadratic $Q\left(\tau^{*}\right)$ is negative. We only need to consider the case $k_{d}^{*}<k_{\mathrm{d}, \mathrm{cr}, \infty}^{*}$. This condition implies that the coefficient $a_{2}$ is positive. From the analysis in appendix $\mathrm{C}$ we deduce that the inequality $Q\left(\tau^{*}\right) \geq 0$ is only true if $0<\tau^{*}<\tau_{+}^{*}$, where $\tau_{+}^{*}$ is defined by equation (47).

\subsubsection{Stability of the no-washout branch}

In appendix D we show that when the no-washout branch is physically meaningful it is stable.

\subsection{Asymptotic solutions}

In this section we obtained asymptotic solutions for large residence times. The case $k_{d}^{*}=1$ is not allowed in the asymptotic formula, because the no-washout branch is not physically meaningful for $k_{d}^{*}=1$. At large residence times, we have

$$
\begin{aligned}
S_{\mathrm{nw}}^{*} & \approx \frac{k_{d}^{*}}{1-k_{d}^{*}}+\frac{\left(1-R^{*}\right)}{\left(1-k_{d}^{*}\right)^{2}} \cdot \frac{1}{\tau^{*}}+O\left(\frac{1}{\tau^{* 2}}\right), \\
X_{\mathrm{b}, \mathrm{nw}}^{*} & \approx a_{0} \cdot \frac{1}{\tau^{*}}+O\left(\frac{1}{\tau^{* 2}}\right), \\
X_{s, n w}^{*} & \approx \frac{X_{s, 0}^{*}+\left(1-f_{p}\right) k_{d}^{*} a_{0}}{k_{h}^{*}} \cdot \frac{1}{\tau^{*}}+O\left(\frac{1}{\tau^{* 2}}\right), \\
X_{p, n w}^{*} & \approx \frac{X_{p, 0}^{*}+f_{p} k_{d}^{*} a_{0}}{1-R^{*}}+\left(b_{0}+a_{0} c_{0}\right) \cdot \frac{1}{\tau^{*}}+O\left(\frac{1}{\tau^{* 2}}\right), \\
X_{i}^{*} & \approx \frac{X_{i, 0}^{*}}{1-R^{*}}, \\
\mathrm{COD}_{\mathrm{nw}}^{*} & \approx \frac{k_{d}^{*}}{1-k_{d}^{*}}+\left\{\frac{\left(1-R^{*}\right)}{\left(1-k_{d}^{*}\right)^{2}}+\frac{\left[X_{s, 0}^{*}+\left(1-f_{p}\right) k_{d}^{*} a_{0}\right] \alpha_{g}}{k_{h}^{*}}\right\} \cdot \frac{1}{\tau^{*}}+O\left(\frac{1}{\tau^{* 2}}\right), \\
\mathrm{VSS}_{\mathrm{nw}}^{*} & \approx \frac{X_{i, 0}^{*}}{1-R^{*}}+\frac{X_{p, 0}^{*}+f_{p} k_{d}^{*}}{1-R^{*}} a_{0}+\left\{b_{0}+a_{0}\left[1+c_{0}+\frac{X_{s, 0}^{*}+\left(1-f_{p}\right) k_{d}^{*}}{k_{h}^{*}}\right]\right\} \cdot \frac{1}{\tau^{*}}+O\left(\frac{1}{\tau^{* 2}}\right),
\end{aligned}
$$

where

$$
\begin{aligned}
a_{0} & =\frac{\operatorname{COD}_{\text {in }}^{*}\left(1-k_{d}^{*}\right)-k_{d}^{*}}{k_{d}^{*}\left(1-k_{d}^{*}\right)\left[\left(1-\left(1-f_{p}\right) \alpha_{g}\right]\right.} \\
b_{0} & =\frac{f_{p}\left[S_{0}^{*}\left(1-k_{d}^{*}\right)^{2}-k_{d}^{*}\left(1-k_{d}^{*}\right)-k_{h}^{*}\right]}{\left(1-k_{d}^{*}\right)^{2}\left[1-\left(1-f_{p}\right) \alpha_{g}\right] k_{h}^{*}} \\
c_{0} & =\frac{-f_{p}\left(k_{d}^{*}+k_{h}^{*}\right)}{\left[1-\left(1-f_{p}\right) \alpha_{g}\right] k_{h}^{*}} .
\end{aligned}
$$

Note that the effluent concentration can not be reduced below the limiting value

$$
\lim _{\tau^{*} \rightarrow \infty} S_{\mathrm{nw}}^{*}=\frac{k_{d}^{*}}{1-k_{d}^{*}}>0
$$

and that the biomass concentration is independent of the value of the effective recycle factor $\left(R^{*}\right)$. 
The leading order term for the chemical oxygen demand is identical to both that in our earlier model [1] and in the basic model [12]. The leading order term for the volatile suspended solids is also identical provided that there are no non-biodegradable particulates in the feed, i.e. $X_{p, 0}^{*}=0$.

\subsection{Steady-state diagram}

Figure 2 shows the steady state diagrams for the four main state variables. (A steady-state diagram is not provided for inert matter, it is a horizontal line). In figure 2 (a) the soluble substrate increases along the washout branch, as shown by equation (34), as additional soluble substrate is produced by the hydrolysis of the insoluble substrate and there is no biomass to consume it. After the transcritical bifurcation the soluble substrate is a decreasing function of the residence time, as shown by equation (42). From equation (53) the soluble substrate concentration approaches the limiting value $S^{*}=k_{d}^{*} /\left(1-k_{d}^{*}\right)$.

Figure 2 (b) shows the steady-state biomass concentration. After the transcritical bifurcation it increases sharply from its zero value along the washout branch to reach a maximum value, $X_{\mathrm{b}, \max }^{*}=8.3789$ when $\tau_{\max }^{*}=4.0546$. Thereafter it decreases towards its limiting value at infinite residence time, give by equation (54): $X_{b}^{*}=0$.

Figure 2 (c) shows that the insoluble substrate concentration decreases with the residence time towards the limiting value zero.

Figure 2 (d) shows the non-biodegradable particulates. Along the washout branch their value is equal to the influent value, in this case zero. After the transcritical bifurcation it increases due to the decay of biomass. From equation (56) the limiting value when the residence time approaches infinity is $\left(X_{p, 0}^{*}+f_{p} k_{d}^{*} a_{0}\right) /\left(1-R^{*}\right)$. This has two components, the first due to the inflow whilst the second is due to the death of biomass.

\subsection{The chemical oxygen demand}

Figure 3 shows the chemical oxygen demand as a function of the residence time when there is no recycle. The chemical oxygen demand is constant along the washout branch $\left(\tau^{*}<\tau_{\mathrm{cr}}^{*}=1.2020\right)$.

$$
\mathrm{COD}_{W}^{*}\left(R^{*}=0\right)=S_{0}^{*}+\frac{\left(1+k_{h}^{*} \tau^{*}\right) \alpha_{g} X_{s, 0}^{*}}{1-R^{*}+k_{h}^{*} \tau^{*}}=S_{0}^{*}+\alpha_{g} X_{s, 0}^{*}=\mathrm{COD}_{\mathrm{in}}^{*}=10.1790 .
$$

Along the no-washout branch the chemical oxygen demand is a decreasing function of the residence time. From equation (58) it has limiting value when the residence time approaches infinity $\left(\tau^{*} \rightarrow \infty\right)$ given by

$$
\lim _{\tau^{*} \rightarrow \infty} \operatorname{COD}_{\mathrm{NW}}^{*}=\frac{k_{d}^{*}}{1-k_{d}^{*}}=0.0732 .
$$

The efficiency at which the chemical oxygen demand is removed can be defined by

$$
E_{\mathrm{COD}^{*}}=\frac{\mathrm{COD}_{\mathrm{in}}^{*}-\mathrm{COD}_{\mathrm{out}}^{*}}{\mathrm{COD}_{\mathrm{in}}^{*}} \text {. }
$$

From equation (63) it follows that the efficiency can not be increased over the limiting value

$$
E_{\mathrm{COD}_{\mathrm{NW}}^{*}}\left(\tau^{*}=\infty\right)=0.9928
$$


Thus it is impossible to remove more that $99.28 \%$ of the chemical oxygen demand flowing into the reactor.

When $E_{\mathrm{COD}^{*}}=0.90$, the chemical oxygen demand in the effluent has been reduced to $90 \%$ of the value in the influent. The required value of the residence time is $\tau^{*}=3.6291$ (16.5 days).

In order to reduce the chemical oxygen demand in the effluent to $1 \%$ of the value in the influent $\left(E_{\mathrm{COD}^{*}}=\right.$ $0.99)$ the required value of the residence time is $\tau^{*}=192.0100$ (872.8 days). Thus in practice an efficiency $\left(E_{\mathrm{COD}^{*}}=0.99\right)$ can not be achieved with a single reactor.

When the effective recycle parameter takes its theoretical maximum $\left(R^{*}=1\right)$ then the residence time to achieve an efficiency $E_{\mathrm{COD}^{*}}=0.99$ is reduced to $\tau^{*}=170.2187$ (773.7 days). This is still too large for practical purposes.

\subsection{The volatile suspended solids}

\subsubsection{The case $R^{*}=0$}

Figure 4 shows a steady state diagram for the volatile suspended solids as a function of the residence time when there is no recycle. Along the washout branch $\left(0<\tau^{*}<\tau_{\text {cr }}^{*}\right)$ we have

$$
\operatorname{VSS}_{W}^{*}\left(R^{*}=0\right)=\frac{X_{p, 0}^{*}+X_{i, 0}^{*}}{1-R^{*}}+\frac{X_{s, 0}^{*}}{1-R^{*}+k_{h}^{*} \tau^{*}}=X_{p, 0}^{*}+X_{i, 0}^{*}+\frac{X_{s, 0}^{*}}{1+k_{h}^{*} \tau^{*}},
$$

which is a decreasing function of the residence time. The volatile suspended solids decrease as insoluble substrate is converted to soluble substrate. The maximum value is when the residence time is zero.

$$
\operatorname{VSS}_{W, \text { max }}^{*}\left(R^{*}=0\right)=\frac{X_{p, 0}^{*}+X_{i, 0}^{*}+X_{s, 0}^{*}}{1-R^{*}}=X_{p, 0}^{*}+X_{i, 0}^{*}+X_{s, 0}^{*}=12.2142 .
$$

Along the washout branch the volatile suspended solids intersects the target value once. The value of the residence time at this intersection point is $\tau_{i, w}^{*}==0.5080$. (See section 5.1.1). At the transcritical bifurcation (47) the volatile suspended solids has decreased to $\operatorname{VSS}_{W}^{*}\left(\tau^{*}=\tau_{\text {cr }}^{*}\right)=1.7432$.

After the transcritical bifurcation the volatile suspended solids is given by equations (41) \& (36). The volatile suspended solids increases to a local maximum, $\mathrm{VSS}_{\mathrm{nw}, \max }^{*}=9.2834$ when $\tau^{*}=3.2167$. Thereafter it decreases toward its limiting value at infinite residence time. From equation (59) we have

$$
\operatorname{VSS}^{*}\left(\tau^{*}=\infty, R^{*}=0\right) \approx \frac{X_{i, 0}^{*}}{1-R^{*}}+\frac{X_{p, 0}^{*}+f_{i} k_{d}^{*}}{1-R^{*}} a_{0}=X_{i, 0}^{*}+X_{p, 0}^{*}+f_{i} k_{d}^{*}=2.1085,
$$

which is below the target value specified by equation (21).

The values of the residence time at the intersection points along the no-washout branch are $\tau_{\mathrm{i}, \mathrm{nw} 1}^{*}=1.2336$ (5.6 days) and $\tau_{\mathrm{i}, \mathrm{nw} 2}^{*}=193.6117$ (880 days). (See section 5.1.2 for how these values are calculated). Thus the volatile suspended solids is guaranteed to be below the target value when $\tau^{*}>\tau_{\mathrm{i}, \mathrm{nw} 2}^{*}=193.6117$. This value is very large in practical terms.

The volatile suspended solids is also lower than the target value if the residence time is between the intersection point on the washout branch and the first intersection point on the no-washout branch. The values of the 
chemical oxygen demand at these intersection points are 10.1790 and 8.4075, corresponding to COD efficiencies of 0 and 0.1740 . Thus it is undesirable to operate in this window of residence times.

The key features of figure 4 are: there are three intersection points, one on the washout branch and two on the no-washout branch; the target value is between the maximum value of the volatile suspended solids along the no-washout branch and the asymptotic value along the no-washout branch. In practice a wastewater treatment plant would have to operate with the residence time larger than the second intersection point on the washout branch to ensure that the volatile suspended solids is below the target value. Using the nomenclature of our earlier work, this response diagram is 'type three' [1].

\subsubsection{The case $R^{*}>0$}

We now investigate how the volatile suspended solids response diagram changes as the value of the effective recycle parameter is varied over the range $0 \leq R^{*}<1$. The mathematical analysis underpinning this discussion is provided in section 5.2 .

In the original Chen and Neethling model as the recycle parameter is increased the 'type three' response diagram becomes 'type four', in which there is only one intersection point on the no-washout branch [1]. In the current model this transition does not occur. Instead, the asymptotic value for the volatile suspended solids at infinite residence time increases through the target value. This leads to a response diagram, type six, containing two intersection points: one on each of the washout and no-washout branches. This response diagram is illustrated in figure 5. The intersection points are at $\tau^{*}=0.5981$ and $\tau^{*}=0.6624$. Figure 5 (a) shows that that volatile suspended solids at the transcritical bifurcation is below the target value whilst 5 (b) indicates that the asymptotic value is higher than the target value.

In type six diagrams the volatile suspended solids can only be maintained below the target value if the reactor is operated at residence times between the two intersection points. However, the corresponding values of the chemical oxygen demand in the effluent at the intersection points, 11.2190 and 10.9734, correspond to COD efficiencies of -0.1022 and -0.0780 . Thus in practice excess sludge formation can not be avoided.

In the original model the final transition, from type four to case five, corresponded to the asymptotic value of the volatile suspended solids at infinity increasing through the target value [1]. In the new model the final transition corresponds to the value of the volatile suspended solids at the transcritical bifurcation increasing through the target value. This leads to the 'type five' response diagram shown in figure 6 . There are now no intersection points and the volatile suspended solids can never be reduced below the target value.

The location of the different regions as a function of the effective recycle parameter is shown in table 1 . The calculation of the transition values is explained in section 5.2.

To summarise, only in the type three response diagram can the volatile suspended solids be kept below the target value whilst simultaneously significantly reducing the chemical oxygen demand. However, it has the twin disadvantages of both requiring a large value for the residence time and restricting the value of the effective 
recycle parameter to: $0 \leq R^{*}<0.3890$.

\section{Discussion}

In section 5.1 we explain how the intersection points of the volatile suspended solids with the target value along the washout and no-washout branches are determined. In section 5.2 we describe how the critical values of the effective recycle parameter are determined, representing the transitions from case three to case six and case six to case five. In section 5.3 we investigate how the volatile suspended solids response diagram depends upon both the effective recycle ratio and the chemical oxygen demand in the feed. We show that if the chemical oxygen demand in the feed is sufficiently high, then the volatile suspended solids is always higher than the target value.

\subsection{Where does the volatile suspended solids equal the target value?}

\subsubsection{Intersection points on the washout branch}

From equation (64) the value of the residence time when the target value is reached on the washout branch is

$$
\tau_{i, w}^{*}=\frac{\left(1-R^{*}\right)\left[X_{p, 0}^{*}+X_{i, 0}^{*}+X_{s, 0}^{*}-\operatorname{VSS}_{t}^{*}\left(1-R^{*}\right)\right]}{\left[\operatorname{VSS}_{t}^{*}\left(1-R^{*}\right)-\left(X_{p, 0}^{*}+X_{i, 0}^{*}\right)\right] k_{h}^{*}} .
$$

This value is physically meaningful only if it is positive and if the target value is lower than the maximum value along the washout branch, which is found by substituting $\tau^{*}=0$ into equation (64), and greater than the value at the washout branch, which is found by substituting $\tau^{*}=\tau_{\mathrm{cr}}^{*}$ in equation (64).

\subsubsection{Intersection point on the no-washout branch}

Intersection points along the no-washout branch happens when expression (41) is equal to the target value. Using equations (35), (36) and (41) intersection points are found to solve the cubic equation

$$
a_{\mathrm{VSS}} \tau^{* 3}+b_{\mathrm{VSS}} \tau^{* 2}+c_{\mathrm{VSS}} \tau^{*}+d_{\mathrm{VSS}}=0
$$

where the coefficients are

$$
\begin{aligned}
a_{\mathrm{VSS}}= & k_{h}^{*} k_{d}^{*}\left(k_{d}^{*} f_{p}+\left(1-k_{d}^{*}\right)\left\{\left[X_{i, 0}^{*}+X_{p, 0}^{*}-\mathrm{VSS}_{\text {target }}^{*}\left(R^{*}-1\right)\right]\left[\left(1-f_{p}\right) \alpha_{g}-1\right]-f_{p}\left[S_{0}^{*}+\alpha_{g} X_{s, 0}^{*}\right]\right\}\right), \\
b_{\mathrm{VSS}}= & \left(1-R^{*}\right)\left\{\left[\mathrm{VSS}_{\text {target }}^{*}\left(1-R^{*}\right)-X_{i, 0}^{*}-X_{p, 0}^{*}\right]\left\{\left\{\left[\left(1-f_{p}\right) \alpha_{g}-2\right] k_{d}^{*}+1\right\} k_{h}^{*}+\left(1-k_{d}^{*}\right) k_{d}^{*}\right\}\right. \\
& \left.+\left[\left(1+S_{0}^{*}+\alpha_{g} X_{s, 0}^{*}\right)\left(1+f_{p}\right) k_{d}^{*}-S_{0}^{*}-\alpha_{g} X_{s, 0}^{*}\right] k_{h}^{*}+\left[\left(S_{0}^{*}+X_{s, 0}^{*}\right)\left(-1+k_{d}^{*}\right)+k_{d}^{*}\right] k_{d}^{*}\right\}, \\
c_{\mathrm{VSS}}= & \left(1-R^{*}\right)^{2}\left\{\left[S_{0}^{*}+X_{i, 0}^{*}+X_{p, 0}^{*}-\mathrm{VSS}_{\text {target }}^{*}\left(1-R^{*}\right)\right]\left(-1+k_{h}^{*}+2 k_{d}^{*}\right)+X_{s, 0}^{*}\left(2 k_{d}^{*}+k_{h}^{*} \alpha_{g}-1\right)\right. \\
& \left.+k_{h}^{*}+2 k_{d}^{*}\right\} \\
d_{\mathrm{VSS}}= & \left(1-R^{*}\right)^{3}\left[1+S_{0}^{*}+X_{i, 0}^{*}+X_{p, 0}^{*}+X_{s, 0}^{*}-\operatorname{VSS}_{\text {target }}^{*}\left(1-R^{*}\right)\right] .
\end{aligned}
$$


For a given value of the effective recycle parameter, $R^{*}$, equation (67) is readily solved to find the corresponding values for the intersection points. These values are only physically meaningful if they are larger than the value of the residence time at the transcritical bifurcation point $\left(\tau_{\mathrm{cr}}^{*}\right)$.

The use of equations (66) and (67) to find the physically meaningful intersection points identified in section 4.7.1, with regard to figures $4-6$, is shown in by table 2 . This table shows all the intersection points, including the physically non-meaningful points.

\subsection{Volatile suspended solids: identifying the critical values of $R^{*}$}

In this section we explain how to determine the values of the effectively recycle parameter at which the volatile suspended solids response diagram changes.

\subsubsection{The transition from case three to case $\operatorname{six}\left(R_{3,6}^{*}=0.3890\right)$.}

This transition occurs when the response diagram changes from having one intersection point along the washout branch and two along the no-washout branch, as in figure 4, to having a single intersection point on both the washout and no-washout branches, as in figure 5, It occurs when the value of the volatile suspended solids in the limit of infinitely large residence time equals the target value. Setting the leading term of equation (59) equal to the target value we find that this transition occurs when

$$
R_{3,6}^{*}=\frac{\mathrm{VSS}_{\mathrm{t}}^{*}-X_{i, 0}^{*}-f_{p} k_{d}^{*} a_{0}}{\mathrm{VSS}_{\mathrm{t}}^{*}}=0.3890
$$

where the coefficient $a_{0}$ is given by equation (60).

It is interesting to observe that the transitional value $R_{3,6}^{*}$ only depends upon the total chemical oxygen demand in the feed $\left(\mathrm{COD}_{\mathrm{in}}^{*}\right)$ and not on the particular values of the soluble substrate $\left(S_{0}^{*}\right)$ and slowly biodegradable particulates $\left(X_{0}^{*}\right)$ in the feed. This follows from the fact that the coefficient $a_{0}$ only depends upon the total chemical oxygen demand in the feed, see equation (60). This result make sense because the transition from case three to case six is governed by the behaviour at infinite residence time and at large residence time almost all of the insoluble substrate is converted to the soluble substrate, see equation (55).

\subsubsection{The transition from case six to case five $\left(R_{6,5}^{*}=04949\right)$.}

This transition occurs when the response diagram changes from having a single intersection point along both of the washout and no-washout branches, as in figure 5 , to having no intersection points, as in figure 6 . The transition occurs when the value of the volatile suspended solids at the transcritical bifurcation is equal to the target value $\left[\operatorname{VSS}^{*}\left(\tau_{+}^{*}\right)=\operatorname{VSS}_{t}^{*}\right]$.

To calculate the value of the volatile suspended at the transcritical bifurcation, as a function of the effective recycle parameter, we first determine the residence time at the transcritical bifurcation using equations (47) 
and (48). This value is then substituted into equation (64) to determine the value for the volatile suspended solids at the transcritical bifurcation. Equating the resulting expression to the target value we find that the transition occurs when either

$$
\begin{aligned}
& R_{6,5}^{*}=1 \text { or } \\
& R_{6,5}^{*}=\frac{\left[\operatorname{VSS}_{t}^{*}-\left(X_{i, 0}^{*}+X_{p, 0}^{*}\right)^{2}\right]\left[1+k_{h}^{*} \tau_{\mathrm{cr}}^{*}\left(R^{*}=0\right)\right]+X_{s, 0}^{*}}{\operatorname{VSS}_{t}^{*}\left[1+k_{h}^{*} \tau_{\mathrm{cr}}^{*}\left(R^{*}=0\right)\right]}=0.4949 .
\end{aligned}
$$

Note that the solution $R_{6,5}^{*}=1$ is invalid because equation (64) is not defined for this value.

As opposed to the value of the effective recycle parameter at the transition from case three to case six $\left(R_{3,6}^{*}\right)$, the critical value for the transition from case six to case five depends upon how the chemical oxygen demand in the feed is partitioned into its two constitutive components. This follows from the definition of the transcritical bifurcation when there is no recycle, see equations (45) \& (46).

\subsubsection{Model simplification}

If we assume that there is neither any inert material nor non-biodegradable particulates in the feed, common assumptions, then equations (68) \& (69) simplify to give

$$
R_{3,6}^{*}=1-\frac{f_{i} k_{d}^{*} a_{0}}{\operatorname{VSS}_{\mathrm{t}}^{*}}=0.3893
$$

and

$$
R_{6,5}^{*}=1+\frac{X_{s, 0}^{*}}{\operatorname{VSS}_{t}^{*}\left[1+k_{h}^{*} \tau_{\mathrm{cr}}^{*}\left(R^{*}=0\right)\right]} \geq 1
$$

Note that in the basic model the degradation products from biomass decay are ignored. This corresponds to setting $\left(f_{i}=0\right)$. In this case $\left(R_{3,6}^{*}=1\right)$. When $X_{i, 0}^{*}=X_{p, 0}^{*}=0$ the value for the effective recycle parameter at the transition from case six to case five is no longer physically meaningful $\left(R_{6,5}^{*}>1\right)$.

\subsection{The effect of changing the chemical oxygen demand in the feed $\left(\mathrm{COD}_{\mathrm{in}}^{*}\right)$}

Figure 7 shows how the volatile suspended solids response diagram depends upon the values of the effective recycle parameter and the chemical oxygen demand in the feed. In the following we show how the regions are determined, this investigation is aided by the methods developed to obtain the critical values obtained in section 5.2 .

We introduce a parameter $A$ and write

$$
\begin{gathered}
S_{0}^{*}=A S_{0, \text { old }}^{*}, \\
X_{s, 0}^{*}=A X_{\mathrm{s}, 0, \text { old }}^{*}, \\
\Rightarrow \mathrm{COD}_{\mathrm{in}}^{*}=A \mathrm{COD}_{\mathrm{in}, \text { old }}^{*},
\end{gathered}
$$


where $S_{0, \text { old }}^{*}$ and $X_{\mathrm{s}, 0 \text {,old }}^{*}$ are the default values for the soluble and insoluble substrate, i.e. $S_{0, \text { old }}^{*}=1.9961$ and $X_{\mathrm{s}, 0, \mathrm{old}}^{*}=12.2133$.

We first note that there is a critical value of $A$, below which process failure occurs for all residence times. Using equations (70) \& (51) we find that

$$
A_{\mathrm{cr}}=\frac{1}{\mathrm{COD}_{\mathrm{in}, \mathrm{old}}^{*}}\left(\frac{k_{d}^{*}}{1-k_{d}^{*}}\right)=0.0072 .
$$

Thus process failure occurs for all residence times when

$$
\mathrm{COD}_{\mathrm{in}}^{*} \leq A_{\mathrm{cr}} \mathrm{COD}_{\mathrm{in}, \mathrm{old}}^{*}=0.0072(0.9105)=0.0066
$$

We first note that for sufficiently small value for $A$ there are two additional response diagrams. In the type one response diagram the target value is larger than the maximum value along the washout branch. Thus the volatile suspended solids concentration in the effluent is always below the target value, i.e. there are no intersection points. In type two the target value is lower than the maximum value along the no-washout branch but higher than the maximum value along the washout branch. Thus there is only one intersection point, which is on the washout branch. The volatile suspended solids at any point on the no-washout branch is below the target value. These response diagrams, shown in figures 8 (a) \& 8 (b), are of limited practical interest as they only occur for low values of the chemical oxygen demand.

From equation (64) the transition from case one to two happens when

$$
\begin{aligned}
\mathrm{VSS}_{t}^{*} & =\frac{1}{1-R^{*}}\left(X_{i, 0}^{*}+X_{p, 0}^{*}+A X_{s, 0}^{*}\right), \\
\Rightarrow A_{12} & =\frac{\operatorname{VSS}_{\mathrm{t}}^{*}\left(1-R^{*}\right)-X_{i, 0}^{*}}{X_{\mathrm{s}, 0, \text { old }}^{*}} .
\end{aligned}
$$

This transition is marked by line 1 in figure 7 .

The transition from case two, where there is one intersection along the washout branch, to case three, when there is one intersection along the washout branch and two intersections along the no-washout branch, occurs when the target value is equal to the maximum value of the volatile suspended solids along the no-washout branch. To find this transition $\left(A_{23}\right)$ we write

$$
G=\mathrm{VSS}_{\mathrm{nw}}^{*}-\mathrm{VSS}_{\mathrm{t}}^{*}
$$

and solve the system

$$
G=0, \quad \frac{\mathrm{d} G}{\mathrm{~d} \tau^{*}}=0
$$

This transition is marked by line 2 in figure 7

The transition from case three, where there is one intersection point along the washout branch and two along the no-washout branch, to case six, where there is a single intersection point on each branch, was investigated 
in section 5.2.1. It occurs when the volatile suspended solids on the no-washout branch at infinite residence time is equal to the target value. Applying the same argument as in section 5.2.1 we find that

$$
A_{36}=\frac{\left(1-k_{d}^{*}\right)\left[\left(1-R^{*}\right) \mathrm{VSS}_{\mathrm{t}}^{*}-X_{i, 0}^{*}\right]\left[1-\alpha_{g}\left(1-f_{p}\right)\right]+f_{p} k_{d}^{*}}{f_{p}\left(1-k_{d}^{*}\right)\left(S_{0}^{*}+\alpha_{g} X_{s, 0}^{*}\right)} .
$$

This transition is marked by line 3 in figure 7 . The case three and case six response diagrams are shown in figures 4 \& 5 respectively.

The transition from case six, where there are two intersection points, one along both the washout and nowashout branches, to case five, where there are no intersection points, was investigated in section 5.2.2. It occurs when the suspended solids along the no-washout branch at the critical value of the residence time is equal to the target value of the volatile suspended solids. Applying the same arguments as in section 5.2.2 we find that

$$
A_{65}=\frac{\left[\left(1-R^{*}\right) \mathrm{VSS}_{\mathrm{t}}^{*}-X_{i, 0}^{*}\right]\left[1+k_{h}^{*} \tau_{\mathrm{cr}}^{*}\left(R^{*}=0\right)\right]}{X_{s, 0}^{*}},
$$

where $\tau_{\mathrm{cr}}^{*}\left(R^{*}=0\right)$ is defined in (48). This transition is marked by line 4 in figure 7 . The case 5 response diagram is shown in figure 6 .

Case six is the 'worst scenario', as the volatile solids are above the target value for all values of the residence time. If the chemical oxygen demand in the feed is sufficiently high, this happens for even in the absence of recycle. Substituting $R^{*}=0$ into the previous equation we find

$$
A_{65, \mathrm{cr}}=\frac{\left[\mathrm{VSS}_{\mathrm{t}}^{*}-X_{i, 0}^{*}\right]\left[1+k_{h}^{*} \tau_{\mathrm{cr}}^{*}\left(R^{*}=0\right)\right]}{X_{s, 0}^{*}} .
$$

\section{Conclusion}

In this paper we analysed an extension of the basic activated sludge model which include additional biochemistry. The additional biochemistry has two components. Firstly, insoluble substrate is included which is hydrolyzed to give soluble substrate. Secondly, the products of biomass decay are included. These comprise slowly biodegradable particulate substrate and non-biodegradable particulate matter. In addition particulate inert matter may be included in the feed. This system contains five equations, rather than two in the basic model. For analysis of the long term behaviour the system of equations can be reduced to three.

We found two steady state solutions corresponding to washout and no-washout branches and determined their stability as a function of the residence time. The washout branch corresponds to process failure and has to be avoided. We showed that if the decay rate is sufficiently high then the process failure is automatic. For values of the decay coefficient below this critical value there exists a critical value of the residence time, corresponding to a transcritical bifurcation. Below this value process failure occurs, above this value the no-washout solution branch is both physically meaningful and stable. From our expression for the solutions along the no-washout branch we obtained asymptotic expressions in the limit of high residence time. 
The steady-state expressions were used to investigate how the reactor performance depends upon process parameters. We examined the chemical oxygen demand in the effluent and the volatile suspended solids. Our main interest was the latter and we investigated how it depends upon the effective recycle parameter, the total chemical oxygen demand in the feed and how the chemical oxygen demand in the feed is partitioned between its two components.

For the default parameter values we found that there are three generic response diagrams for the steady-state concentration of volatile suspended solids. In the first case (called case three to be consistent with our analyse of a related model [1]) it is possible to ensure that the suspended solids are below the target value by operating at sufficiently high residence times. However, the required minimum value of the residence time may be unpalatable in practice. In the second case (case six), it is only possible to ensure that the suspended solids are below the target value by operating the reactor in a very restrictive range of residence times. Over this range there is effective no removal of chemical oxygen demand. Thus this scenario is not of practical interest. In the final case (case five) for any value of the residence time the volatile suspended solids are always above the target value.

For the model considered in this paper it seems inevitably, except for very dilute wastewaters, that for practical values of the residence time that the suspended solids will eventually exceed the target value. When this happens plant operation must cease, so that the sludge can be removed from the reactor. Is it possible to prevent this from happening by operating a sludge disintegration unit in situ? We have investigated this possibility for the original Chen and Neethling model and some results along these lines are available [2].

The model investigated here is much simpler than those developed by the IWA [6]. It has the advantage that it is possible to obtain analytic expression for the steady-state expressions. In turn these allow gain considerable insight to be obtained into its generic behaviour. It is hoped that these insights will be informative in the study of the various IWA models, where analytic expressions for the steady-states are unavailable and purely numerical techniques must be deployed. A start on investigating ASM-1 using continuation methods is presented in [13].

\section{Acknowledgements}

AA is grateful to the High Education Ministry of Saudi Arabia for a PhD scholarship.

\section{A Nomenclature}

Subscripts $n w$ and $w$ indicate properties along the no-washout and washout branches respectively.
Abbreviation Explanation
C The recycle concentration factor
COD Chemical oxygen demand.
$\mathrm{COD}=S+X_{S}$

Unit

$(-)$ 
COD* Scaled chemical oxygen demand.

$\mathrm{COD}^{*}=S^{*}+\alpha_{g} X_{s}^{*}$

$\mathrm{COD}_{i n}^{*} \quad$ Chemical oxygen demand in the feed.

$\mathrm{COD}_{i n}^{*}=S_{0}^{*}+\alpha_{g} X_{s, 0}^{*}$

$E_{\mathrm{COD}}^{*} \quad$ Chemical oxygen demand removal efficiency

$E_{\mathrm{COD}}^{*}=\left(\mathrm{COD}_{\mathrm{in}}^{*}-\mathrm{COD}^{*}\right) / \mathrm{COD}_{\text {in }}^{*}$

F

Flow rate through bioreactor

$\left(\mathrm{dm}^{3} \mathrm{hr}^{-1}\right)$

$K_{s} \quad$ Monod constant

$R \quad$ Recycle ratio based on volumetric flow rates

$R^{*} \quad$ Effective recycle parameter

$R^{*}=(C-1) R$

$S \quad$ Substrate concentration within the bioreactor

$S^{*} \quad$ Dimensionless substrate concentration

$S^{*}=S / K_{s}$

$S_{0} \quad$ Concentration of substrate in the feed

$S_{0}^{*} \quad$ Dimensionless feed concentration

$S_{0}^{*}=S_{0} / K_{s}$

V

Bioreactor volume

Volatile suspended solids

$\mathrm{VSS}=X_{b}+X_{s}+X_{p}+X_{i}$

VSS* Scaled volatile suspended solids

$\mathrm{VSS}^{*}=X_{b}^{*}+X_{s}^{*}+X_{p}^{*}+X_{i}^{*}$

VSS $_{\text {target }}$ Target value of the volatile suspended solids

$\mathrm{VSS}_{\mathrm{t}}^{*} \quad$ Scaled target value

$\mathrm{VSS}_{\text {target }}^{*}=\mathrm{VSS}_{\text {target }} /\left(\alpha_{g} K_{s}\right)$

$X_{b}$

Concentration of biomass

Concentration of particulate inert material

Concentration of slowly biodegradable particulate

Concentration of non-biodegradable particulate

Concentration in the feed $(\mathrm{j}=\mathrm{b}, \mathrm{s}, \mathrm{p}, \mathrm{i})$

Scaled Concentration in the feed $(\mathrm{j}=\mathrm{b}, \mathrm{s}, \mathrm{p}, \mathrm{i})$

$X_{j, 0}^{*}=X_{j, 0} /\left(\alpha_{g} K_{s}\right)$

$X_{j}^{*} \quad$ Dimensionless concentration $(\mathrm{j}=\mathrm{b}, \mathrm{s}, \mathrm{p}, \mathrm{i})$

$X_{j}^{*}=X_{j} /\left(\alpha_{g} K_{s}\right)$

$X_{t} \quad$ Total volatile suspended solids

The fraction of dead biomass converted to non-biodegradable particulate

Death coefficient

$k_{d}$

Dimensionless decay coefficient 


$$
k_{d}^{*}=k_{d} / \mu_{m}
$$

$k_{h} \quad$ Hydrolysis rate of insoluble organic compounds

$k_{h}^{*} \quad$ Dimensionless hydrolysis rate

$$
k_{h}^{*}=k_{h} / \mu_{m}
$$

$t \quad$ Time $\quad\left(\mathrm{hr}^{-1}\right)$

$t^{*} \quad$ Dimensionless time $\quad(-)$

$t^{*}=\mu_{m} t$

$\alpha_{g} \quad$ Yield factor for growth of biomass $\quad\left(|S||S|^{-1}\right)$

$\beta_{i} \quad$ Conversion efficiency from non-biodegradable particulates to readily biodegradable (soluble) substrate,

$\mu(S)$

Specific growth rate model

$\tau^{*} \quad$ Scaled residence time

$$
\tau^{*}=\mu_{m} \tau
$$

We take the units of soluble substrate to be: $|S|=\mathrm{g}^{\mathrm{COD} \mathrm{dm}}{ }^{-3}$.

We assume that $C \geq 1$, as otherwise recycle leads to a decrease in reactor performance.

The cases $R^{*}=0,0<R^{*}<1$ and $R^{*}=1$ represent a flow reactor without recycle, a flow reactor with non-idealized recycle, and a flow reactor with idealized recycle, respectively.

\section{B Values of parameters}

Typical dimensional parameter values are taken from [19]. $K_{s}=5,190|S|, S_{0}=10,360|S|$, VSS $\mathrm{S}_{\text {target }}=$ $12,000|S| . \quad X_{b, 0}=0|S|, X_{i, 0}=3|S|, X_{p, 0}=0|S|, X_{s, 0}=42,469.20|S|, f_{p}=0.08, k_{d}=0.015$ day $^{-1}$, $k_{h}=1.1 \mathrm{day}^{-1}, \alpha_{g}=0.67, \mu_{m}=0.22 \mathrm{day}^{-1}$.

The dimensionless parameter values are: $S_{0}^{*}=1.9961, \mathrm{VSS}_{t}^{*}=3.4510 . X_{b, 0}^{*}=0, X_{i, 0}^{*}=0.0009, X_{p, 0}^{*}=0$, $X_{s, 0}^{*}=12.2133, f_{p}=0.08, k_{d}^{*}=0.0682, k_{h}^{*}=5$.

\section{$\mathrm{C}$ When is the no-washout branch physically meaningful?}

The no-washout branch is physically meaningful only when the substrate and cellmass concentrations are positive $\left(S_{n w}^{*} \geq 0\right.$ and $\left.X_{b n w}^{*} \geq 0\right)$. We have

$$
S_{n w}^{*}=\frac{1-R^{*}+k_{d}^{*} \tau^{*}}{R^{*}-1+\left(1-k_{d}^{*}\right) \tau^{*}}, \quad X_{b n w}^{*}=\frac{\left(a S_{n w}^{* 2}+b S_{n w}^{*}+c\right)\left[R^{*}-1+\left(1-k_{d}^{*}\right) \tau^{*}\right]}{\left(a_{1} \tau^{* 2}+b_{1} \tau^{*}+c_{1}\right) \tau^{*}}
$$


where the coefficients are

$$
\begin{array}{ll}
a=1-R^{*}+k_{h}^{*} \tau^{*} \geq 0, & a_{1}=\left[\left(1-f_{p}\right) \alpha_{g}-1\right] k_{h}^{*} k_{d}^{*}<0, \\
b=\left(1-R^{*}\right)\left(1-S_{0}^{*}\right)+\left(1-S_{0}^{*}-\alpha_{g} X_{s, 0}^{*}\right) k_{h}^{*} \tau^{*}, & b_{1}=\left(R^{*}-1\right)\left(k_{h}^{*}+k_{d}^{*}\right)<0, \\
c=\left(R^{*}-1\right) S_{0}^{*}-\left(S_{0}^{*}+\alpha_{g} X_{s, 0}^{*}\right) k_{h}^{*} \tau^{*}<0, & c_{1}=-\left(R^{*}-1\right)^{2}<0 .
\end{array}
$$

The substrate concentration is positive only when its denominator is positive. This gives the condition

$$
\tau^{*}>\tau_{\mathrm{pm}, 1}^{*}=\frac{1-R^{*}}{1-k_{d}^{*}}
$$

where we also require

$$
0 \leq k_{d}^{*}<1 . \quad \text { Recall that }\left(0 \leq R^{*} \leq 1\right)
$$

We now investigate the condition for the biomass concentration to be positive. We write the biomass concentration in the form

$$
\begin{aligned}
X_{b n w}^{*} & =\frac{Q\left(S_{n w}^{*}\right)}{B\left(\tau^{*}\right)} \cdot \frac{A}{\tau^{*}}, \\
A & =R^{*}-1+\left(1-k_{d}^{*}\right) \tau^{*}, \\
B\left(\tau^{*}\right) & =\left(a_{1} \tau^{* 2}+b_{1} \tau^{*}+c_{1}\right) \tau^{*}, \\
Q\left(S_{n w}^{*}\right) & =a S_{n w}^{* 2}+b S_{n w}^{*}+c,
\end{aligned}
$$

where the coefficients $a_{1}, b_{1}$ and $c_{1}$ are given by equations (72)-(74).

Inequality (75) establishes that $A>0$. We now note that from equations (72)-(74) the coefficients $a, b$ and $c$ are all negative. As we need only consider positive values for the residence time $\left(\tau^{*}>0\right)$ we conclude that the quadratic function $B\left(\tau^{*}\right)$ is negative. Thus the condition for the biomass concentration to be positive is

$$
Q\left(S_{n w}^{*}\right)<0
$$

We now consider the quadratic function

$$
Q\left(S_{n w}^{*}\right)=a S_{n w}^{* 2}+b S_{n w}^{*}+c,
$$

where the coefficients are defined in equations (72)-(74). We have

$$
Q\left(S_{n w}^{*}=0\right)=c<0 .
$$

As $a>0$ the quadratic equation $Q=0$ has real solutions

$$
S_{n w}^{*}=S_{n w,-}^{*}<0 \quad \text { and } \quad S_{n w}^{*}=S_{n w,+}^{*}>0 .
$$

As only positive values for $S_{n w}^{*}$ are physically meaningful, the condition for the biomass concentration to be positive is given by

$$
0 \leq S_{n w}^{*} \leq S_{n w,+}^{*}=\frac{-b+\sqrt{b^{2}-4 a c}}{2 a}
$$


Substituting for the steady-state soluble substrate concentration, equation (71), we find, after some algebra, that the condition for the biomass concentration to be positive is given by

$$
\begin{aligned}
Q\left(\tau^{*}\right) & =q_{2} \tau^{* 2}+q_{1} \tau^{*}+q_{0} \geq 0, \\
q_{2} & =\left[\left(1-k_{d}^{*}\right)\left(S_{0}^{*}+\alpha_{g} X_{s, 0}^{*}\right)-k_{d}^{*}\right] k_{h}^{*}, \\
q_{1} & =-\left(1-R^{*}\right)\left[\left(S_{0}^{*}+\alpha_{g} X_{s, 0}^{*}\right) k_{h}^{*}-\left(1-k_{d}^{*}\right) S_{0}^{*}+k_{d}^{*}+k_{h}^{*}\right], \\
q_{0} & =-\left(1-R^{*}\right)^{2}\left(1+S_{0}^{*}\right) .
\end{aligned}
$$

Note that

$$
Q\left(\tau^{*}=0\right)=q_{0}<0
$$

It can be shown that the biomass concentration is not physically meaningful if $a_{2} \leq 0$. When $a_{2}>0$ the quadratic equation has roots $\tau^{*}=\tau_{-}^{*}<0$ and $\tau^{*}=\tau_{+}^{*}>0$. We have not considered inequality (75). We have

$$
\begin{aligned}
Q\left(\tau^{*}=\tau_{\mathrm{pm}, 1}^{*}\right) & =\frac{\left(k_{d}^{*}-k_{h}^{*}\right)\left[1+R^{*}\left(R^{*}-2\right)\right]-\left(R^{*}-1\right)^{2}}{\left(1-k_{d}^{*}\right)^{2}}, \\
& <Q_{1}=\frac{k_{d}^{*}\left[1+R^{*}\left(R^{*}-2\right)\right]-\left(R^{*}-1\right)^{2}}{\left(1-k_{d}^{*}\right)^{2}} .
\end{aligned}
$$

The function $Q_{1}$ is maximised when $R^{*}=1$. Thus

$$
Q\left(\tau^{*}=\tau_{\mathrm{pm}, 1}^{*}\right)<Q_{1}\left(R^{*}=1\right)=0 .
$$

From this we deduce that

$$
0<\tau_{p m, 1}^{*}<\tau_{+}^{*}
$$

Thus the conditions that the no-washout branch be physically meaningful are

$$
\begin{aligned}
& \tau^{*} \geq \tau_{+}^{*}=\frac{-q_{1}+\sqrt{q_{1}^{2}-4 q_{2} q_{0}}}{2 q_{2}}, \\
& q_{2}>0 .
\end{aligned}
$$

\section{Stability of the no-washout branch}

We are only interested in the stability of the no-washout branch when it is physically stable. Hence we assume that: $S_{n w}^{*}>0, X_{b n w}^{*}>0$, and $X_{s n w}^{*}>0$.

The Jacobian matrix for the no-washout branch is given by

$$
J\left(S_{n w}^{*}, X_{b n w}^{*}, X_{\text {snw }}^{*}\right)=\left(\begin{array}{ccc}
f_{1} & f_{2} & f_{3} \\
g_{1} & 0 & 0 \\
0 & h_{2} & h_{3}
\end{array}\right) .
$$


The coefficients in the Jacobian matrix are

$$
\begin{array}{ll}
f_{1}=-\frac{1}{\tau^{*}}-\frac{X_{b n w}^{*}}{\left(1+S_{n w}^{*}\right)^{2}}<0, & g_{1}=\frac{X_{b n w}^{*}}{\left(1+S_{n w}^{*}\right)^{2}}>0, \\
f_{2}=-\frac{S_{n w}^{*}}{1+S_{n w}^{*}}<0, & h_{2}=\left(1-f_{p}\right) k_{d}^{*}>0, \\
f_{3}=\alpha_{g} k_{h}^{*}>0, & h_{3}=\frac{R^{*}-1}{\tau^{*}}-k_{h}^{*}<0 .
\end{array}
$$

The characteristic polynomial of the Jacobian matrix (81) is given by

$$
\begin{aligned}
\lambda^{3}+d_{1} \lambda^{2}+d_{2} \lambda+d_{3} & =0 \\
d_{1} & =-\left(h_{3}+f_{1}\right)>0 \\
d_{2} & =-\left(g_{1} f_{2}-h_{3} f_{1}\right)>0 \\
d_{3} & =g_{1}\left(f_{2} h_{3}-h_{2} f_{3}\right) .
\end{aligned}
$$

By the Routh-Hurwitz criteria [10] the polynomial (82) has negative real roots when

$d_{1}>0, \quad d_{3}>0 \quad$ and $\quad d_{1} d_{2}-d_{3}>0$

Consider the first condition $d_{1}>0$. We have

$$
\begin{aligned}
d_{1} & =-\left(h_{3}+f_{1}\right) \\
& =-\left(\frac{R^{*}-1}{\tau^{*}}-k_{h}^{*}-\frac{1}{\tau^{*}}-\frac{X_{b n w}^{*}}{\left(1+S_{n w}^{*}\right)^{2}}\right)>0 .
\end{aligned}
$$

Consider the second condition $d_{3}>0$. We have

$$
d_{3}=g_{1}\left(f_{2} h_{3}-h_{2} f_{3}\right)
$$

As $g_{1}>0$ the condition $d_{3}>0$ becomes

$$
d_{3}>0 \Rightarrow f_{2} h_{3}-h_{2} f_{3}>0 \Rightarrow \frac{S_{n w}^{*}}{1+S_{n w}^{*}}\left(\frac{1-R^{*}}{\tau^{*}}+k_{h}^{*}\right)-\left(1-f_{p}\right) k_{d}^{*} \alpha_{g} k_{h}^{*}>0
$$

After some work we have

$$
f_{2} h_{3}-h_{2} f_{3}>0 \Rightarrow \frac{-\left(i_{1} \tau^{* 2}+j_{1} \tau^{*}+k_{1}\right)}{\tau^{* 2}}>0
$$

where

$$
\begin{aligned}
& i_{1}=-k_{d}^{*} k_{h}^{*}\left[1-\left(1-f_{p}\right) \alpha_{g}\right]<0, \quad \text { as }\left(1-f_{p}\right) \alpha_{g} \leq 1 \\
& j_{1}=-\left(k_{d}^{*}+k_{h}^{*}\right)\left(1-R^{*}\right)<0, \\
& k_{1}=\left(1-R^{*}\right)^{2}>0 .
\end{aligned}
$$


The condition $d_{3}>0$ reduces to showing when

$$
Q_{1}\left(\tau^{*}\right)=-\left(i_{1} \tau^{* 2}+j_{1} \tau^{*}+k_{1}\right)>0
$$

As $i_{1}>0, j_{1}>0, k_{1}>0$ this is always true.

Now we consider the final condition $d_{1} d_{2}-d_{3}>0$. We have

$$
\begin{aligned}
d_{1} d_{2}-d_{3} & =\left(h_{3}+f_{1}\right)\left(g_{1} f_{2}-h_{3} f_{1}\right)+g_{1}\left(h_{2} f_{3}-f_{2} h_{3}\right), \\
& =g_{1}\left(f_{1} f_{2}+h_{2} f_{3}\right)-f_{1} h_{3}\left(f_{1}+h_{3}\right), \\
& =\frac{\left(1-f_{p}\right) k_{d}^{*} \alpha_{g} k_{h}^{*} X_{b n w}^{*}}{\left(1+S_{n w}^{*}\right)^{2}}+\left[\frac{1}{\tau^{*}}+\frac{X_{b n w}^{*}}{\left(1+S_{n w}^{*}\right)^{2}}\right] \\
& +\left[\left(\frac{2-R^{*}}{\tau^{*}}+\frac{X_{b n w}^{*}}{\left(1+S_{n w}^{*}\right)^{2}}+k_{h}^{*}\right)\left(\frac{1-R^{*}}{\tau^{*}}+k_{h}^{*}\right)+\frac{S_{n w}^{*} X_{b n w}^{*}}{\left(1+S_{n w}^{*}\right)^{3}}\right]>0,
\end{aligned}
$$

Hence, the no-washout solution branch is always stable when it is physically meaningful.

\section{References}

[1] A.O.M. Alharbi, M.I. Nelson, A.L. Worthy, H.S. Sidhu. In Proceedings of the Australian Chemical Engineering Conference, 2013. http://www. conference.net.au/chemeca2013/papers/29490.pdf

[2] A.O.M. Alharbi, M.I. Nelson, A.L. Worthy, H.S. Sidhu. ANZIAM J., 2014; 55, C348-C367. http:// journal.austms.org.au/ojs/index.php/ANZIAMJ/article/view/7803 [August 7, 2014].

[3] Y-C. Chung, J.B. Neethling. Journal of Environmental Engineering, 1990; 116, 330-342.

[4] A. Fenu, G. Guglielmi, J. Jimenez, M. Spe‘randio, D. Saroj, B. Lesjean, C. Brepols, C. Thoeye, I. Nopens. Water Research, 2010; 44, 4272-4294.

[5] H. Hauduc, L. Rieger, A. Oehmen, M.C.M. van Loosdrecht, Y. Comeau, A. Heduit, P.A. Vanrolleghem, S. Gillot. Biotechnology and Bioengineering, 2013; 110, 24-46.

[6] M. Henze. Activated sludge models ASM1, ASM2, ASM2d and ASM3 IWA, London, 2000.

[7] A.W. Lawrence. In Anaerobic Biological Treatment Processes, (Ed.: F.G. Pohland), American Chemical Society, 1971; pp.163-190.

[8] A.W. Lawrence, P.L. McCarty. Journal of the Sanitary Engineering Division, the American Society of Civil Engineers, 1970; 96, 757-778.

[9] J. Makinia. Mathematical modelling and computer simulation of activated sludge systems. IWA Publishing, London, 2010. 
[10] R. M. May. Stability and complexity in model ecosystems. Princeton University Press, Princeton, N.J, 1973.

[11] C.J. Moretti, D. Das, B.T. Kistner, H. Gullicks, Y-T Hung. Water, 2011, 3, 806-818.

[12] M.I. Nelson, T. Kerr, X.D. Chen. Asia Pacific Journal of Chemical Engineering, 2008, 3, 70-80.

[13] M.I. Nelson and H.S. Sidhu. Applied Mathematics Letters, 2009; 22, 629-635. dx.doi.org/10.1016/j . aml.2008.05.003.

[14] A.N.L. Ng, A.S. Kim. Desalination, 2007; 1, 261-281.

[15] D. Orhon, F.G. Babuna, and O. Karahan. Industrial wastewater treatment by activated sludge. IWA Conference, London, 2009.

[16] E.A. Pearson. In Advances in water quality improvement (eds.: E.F. Gloyna, W.W. Eckenfelder). University of Texas Press, Austin, TX, 1968, pp.381-394.

[17] R. Seviour, P. H. Nielsen. Microbial ecology of activated sludge. IWA Publishing, 2010.

[18] S. Yoon. Water Research, 2003; 37, 1921-1931.

[19] S-H Yoon, S. Lee. Water Research, 2005, 39; 3738-3754. 
Table 1: The generic behavior of the reactor as a function of the effective recycle parameter.

\begin{tabular}{|l|c|c|c|}
\hline$R^{*}$ & $\tau_{+}^{*}$ & $\tau_{i, w}^{*}$ & $\tau_{\mathrm{i}, \mathrm{nw}}^{*}$ \\
\hline \hline 0 & 1.2020 & 0.5080 & $1.2336,193.6117,-0.300$ \\
\hline 0.45 & 0.6611 & 0.5981 & $0.6624,-0.1559,-836.0853$ \\
\hline
\end{tabular}

Table 2: The value of the critical value of the residence time $\left(\tau_{+}^{*}\right)$ and the intersection points along the washout and the no-washout branch found using equations 66 and (67) respectively. 


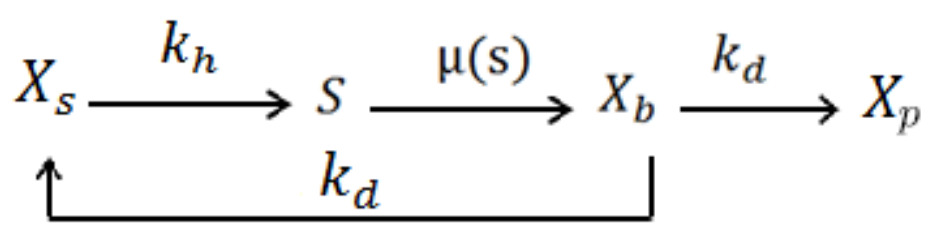

Figure 1: Overview of biochemical processes. Nomenclature: $S$ is the concentration of soluble substrate, $X_{b}$ is the concentration of biomass, $X_{p}$ is the concentration of non-biodegradable particulate material, $X_{s}$ is the concentration of slowly biodegradable particulate substrate, $\mu(s)$ is the specific growth rate, $k_{d}$ is the death coefficient, $k_{h}$ is the hydrolysis rate of insoluble organic compound $\left(X_{s}\right)$ and $\mu(s)$ is the specific growth rate. 


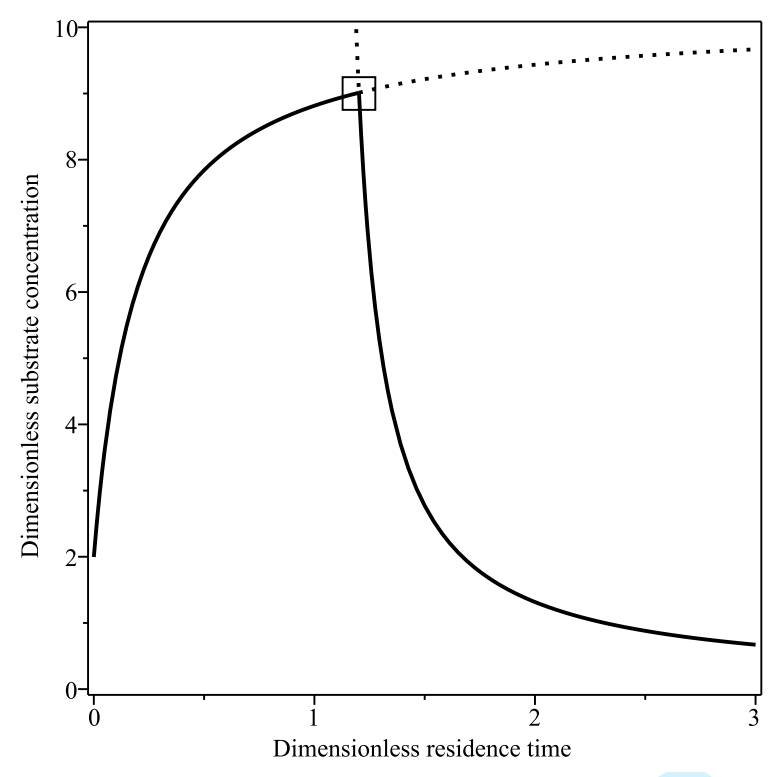

(a) Soluble substrate $\left(S^{*}\right)$

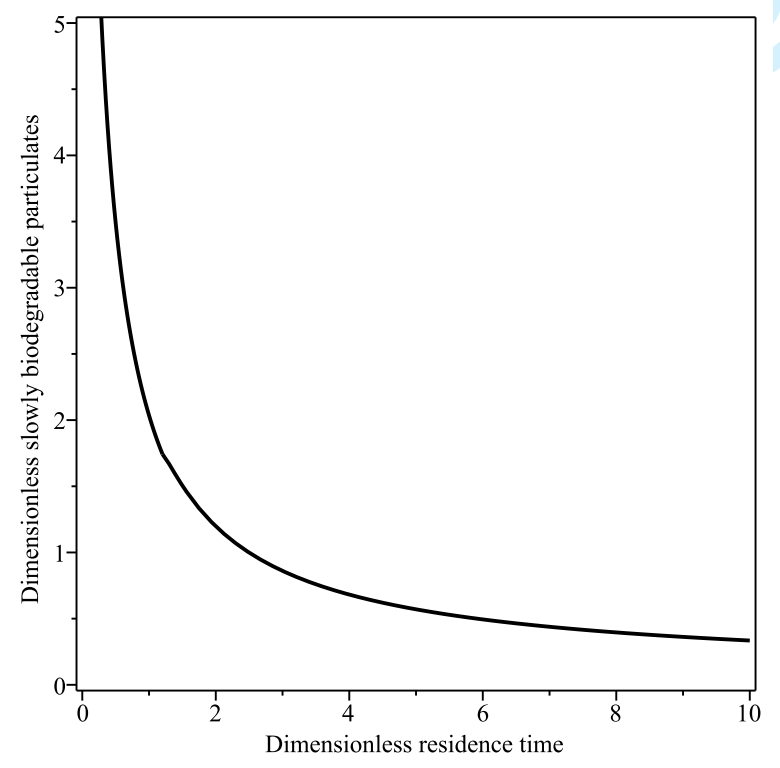

(c) Slowly biodegradable substrate $\left(X_{s}^{*}\right)$

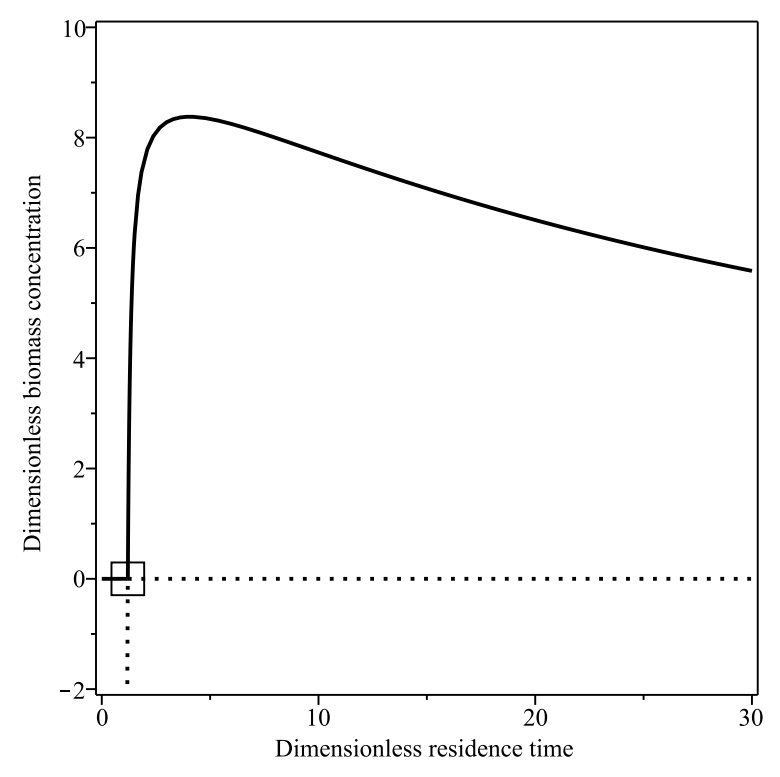

(b) Biomass $\left(X_{b}^{*}\right)$

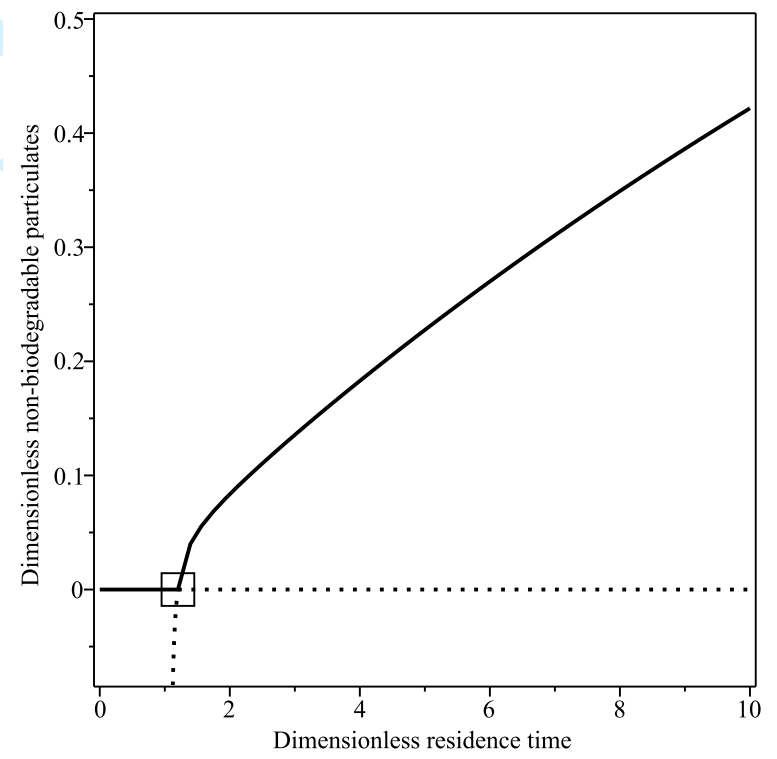

(d) Non-biodegradable particulates $\left(X_{p}^{*}\right)$

Figure 2: Steady-state diagrams showing the variation of dimensionless substrate concentration $\left(S^{*}\right)$, biomass concentration $\left(X_{b}^{*}\right)$, slowly biodegradable particulates concentration $\left(X_{s}^{*}\right)$, and non-biodegradable particulates concentration $\left(X_{p}^{*}\right)$ as a function of the dimensionless residence time $\left(\tau^{*}\right)$. Parameter value $R^{*}=0$. 


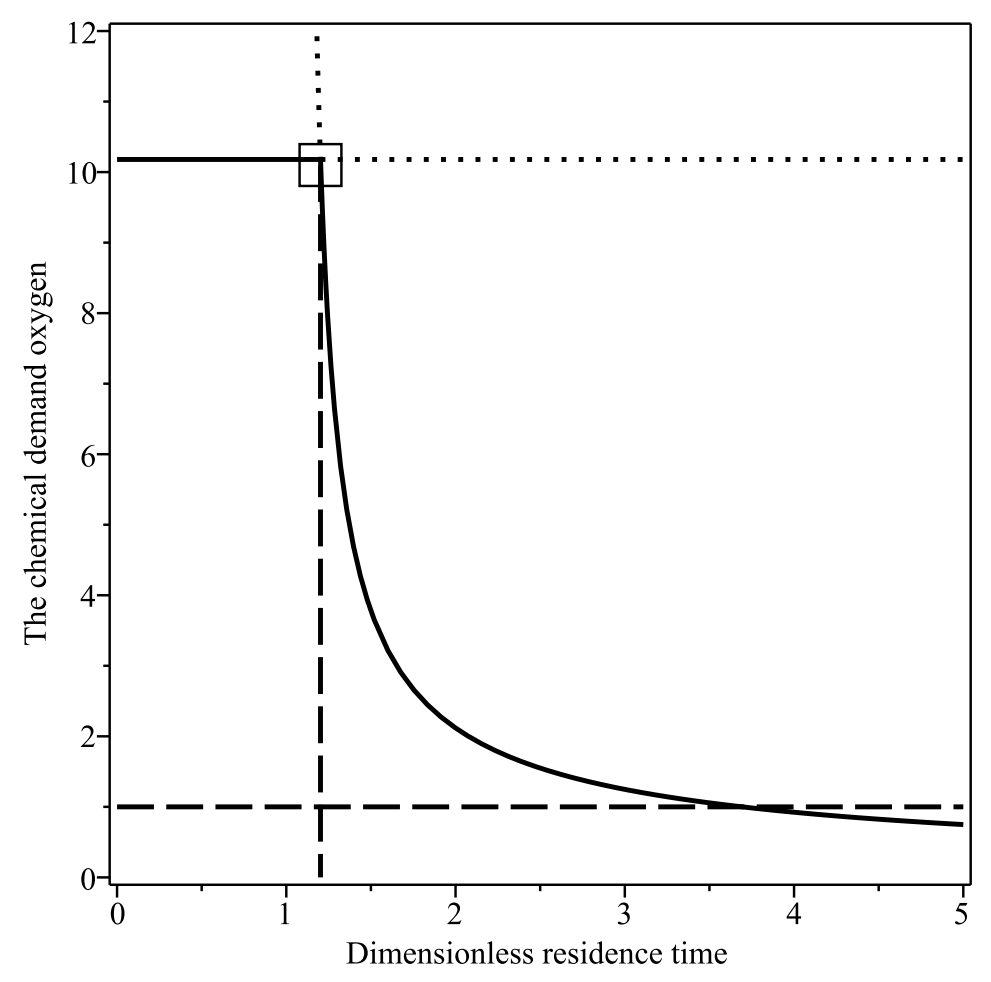

Figure 3: Steady state diagram for the chemical oxygen demand. Parameter value $R^{*}=0$. The horizontal line correspond to a chemical oxygen demand removal efficiency of $90 \%$.

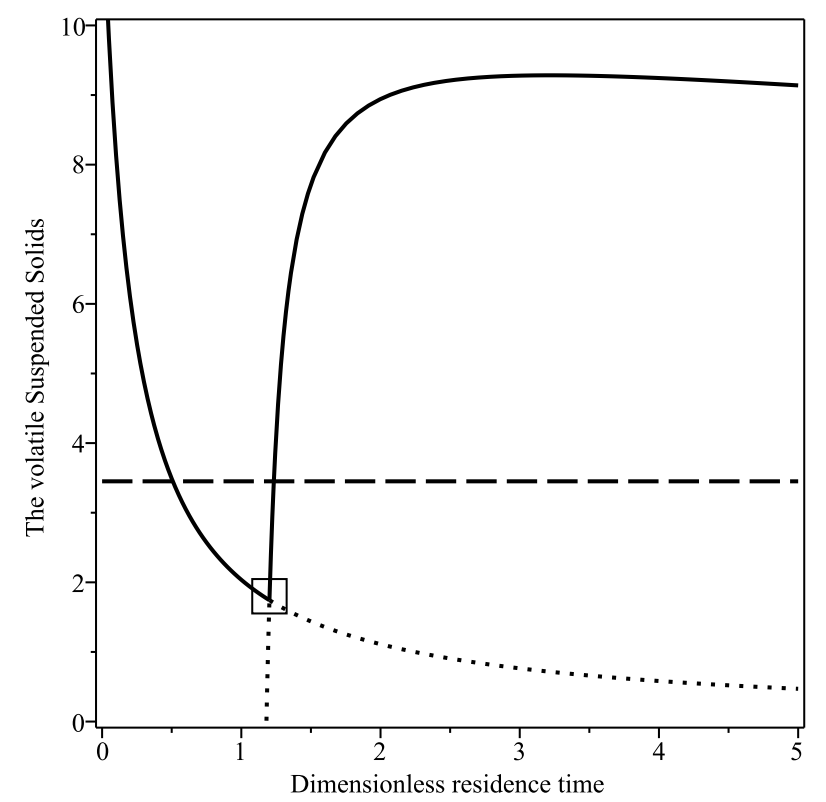

(a) $0 \leq \tau^{*} \leq 5$

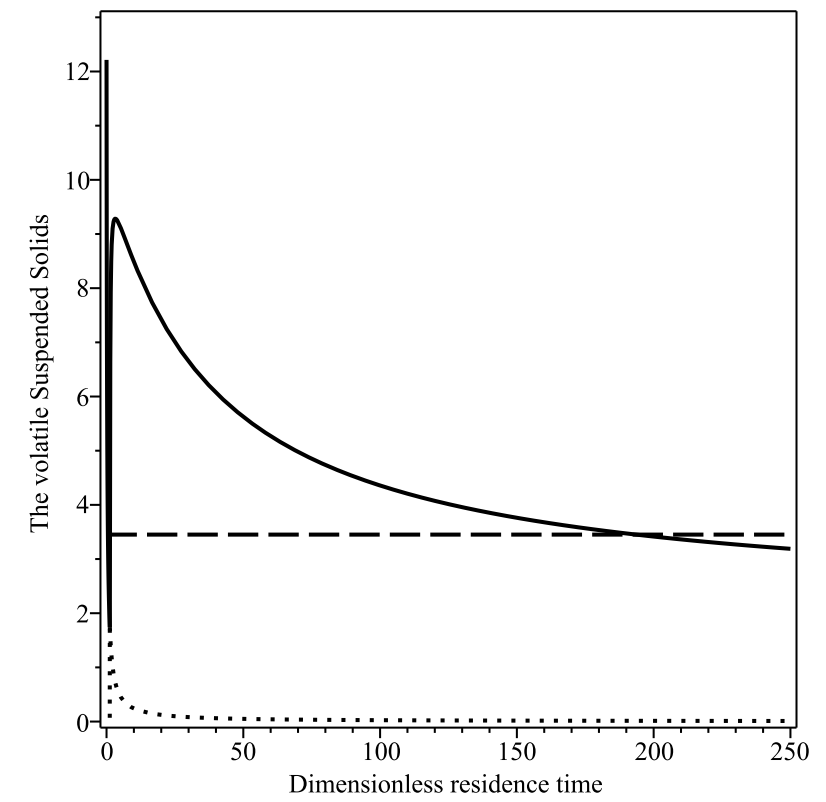

(b) $0 \leq \tau^{*} \leq 250$

Figure 4: Steady state diagram for the volatile suspended solids (type three). Parameter values $R^{*}=0, \tau_{\mathrm{cr}}^{*}=$ 1.2020. The horizontal line denotes the target value of the volatile suspended solids $\left(\operatorname{VSS}_{\text {target }}^{*}=3.5410\right)$. 


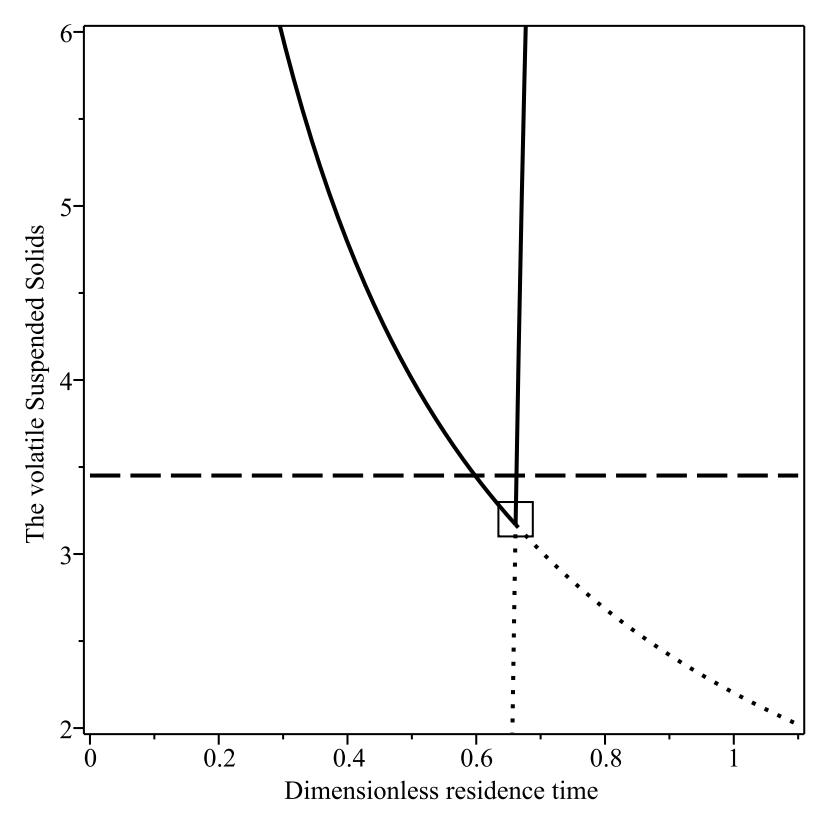

(a) $0 \leq \tau^{*} \leq 1$

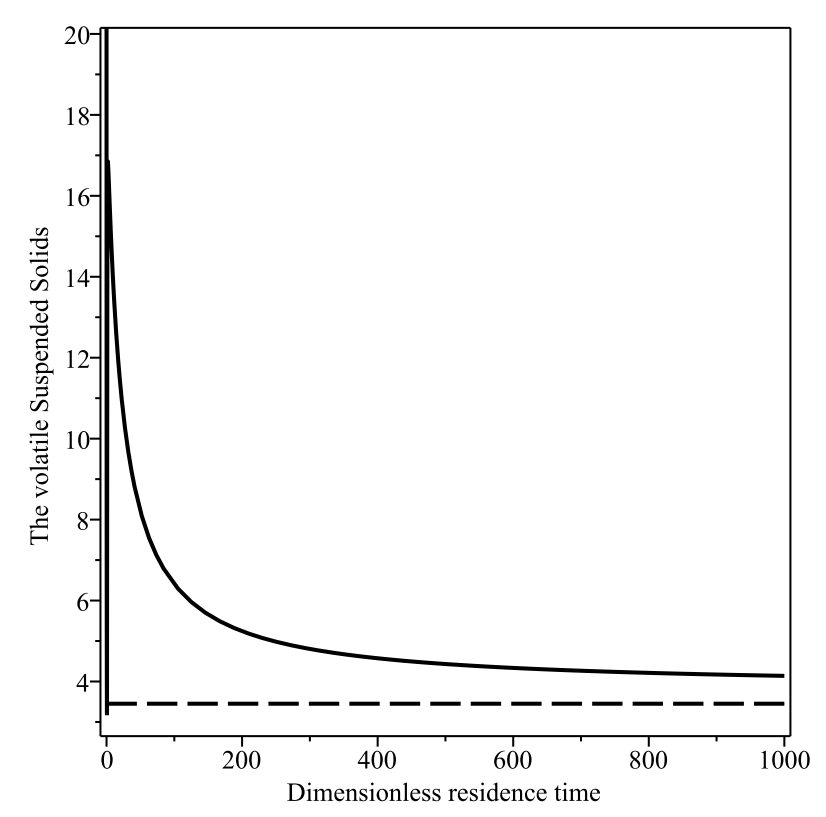

(b) $0 \leq \tau^{*} \leq 1000$

Figure 5: Steady state diagram for the volatile suspended solids (type six). Parameter value $R^{*}=0.45, \tau_{\text {cr }}^{*}=$ 0.6611. The horizontal line denotes the target value of the volatile suspended solids.
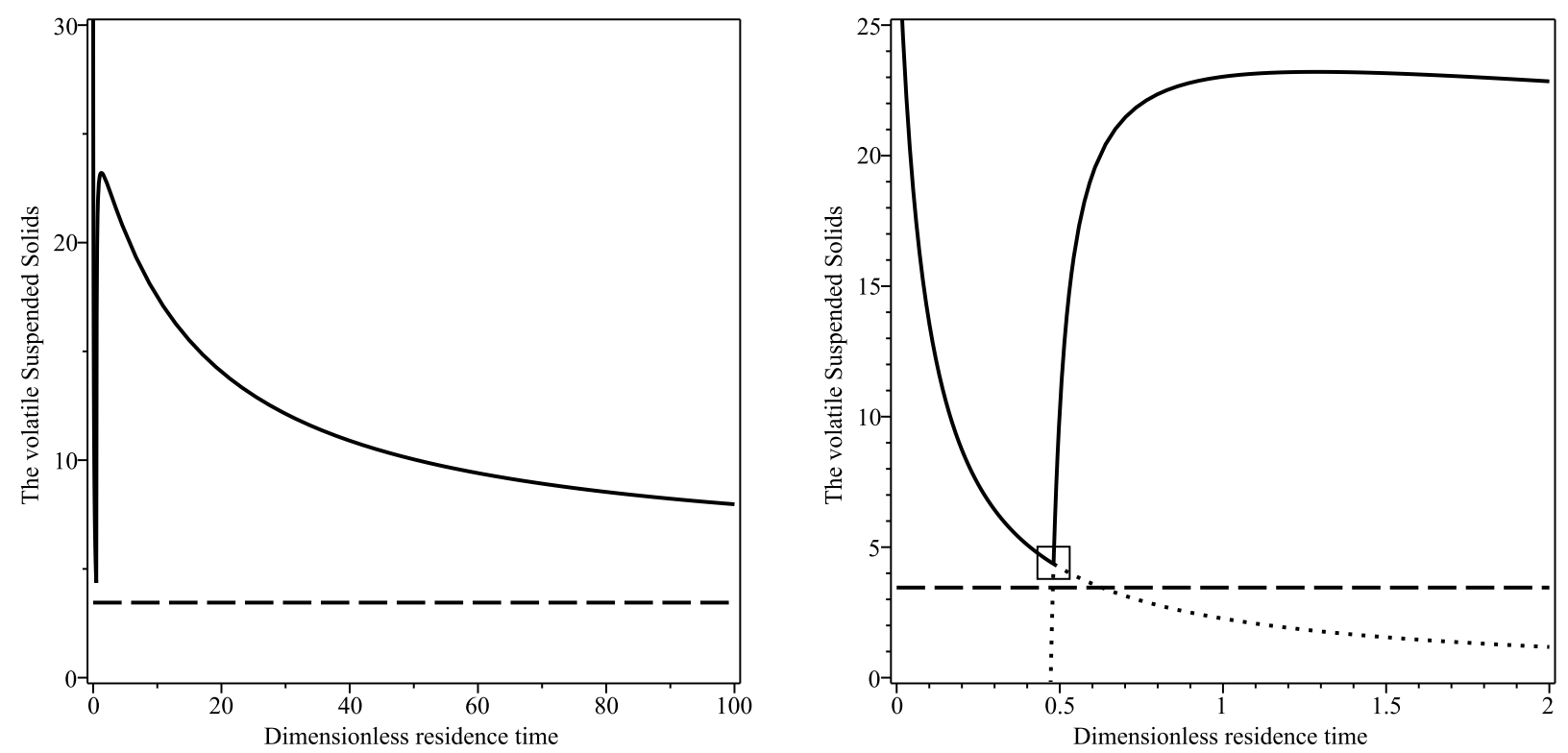

Figure 6: Steady state diagram for the volatile suspended solids (type five). Parameter value $R^{*}=0.6$, $\tau_{\mathrm{cr}}^{*}=0.4808$. The horizontal line denotes the target value of the volatile suspended solids. 


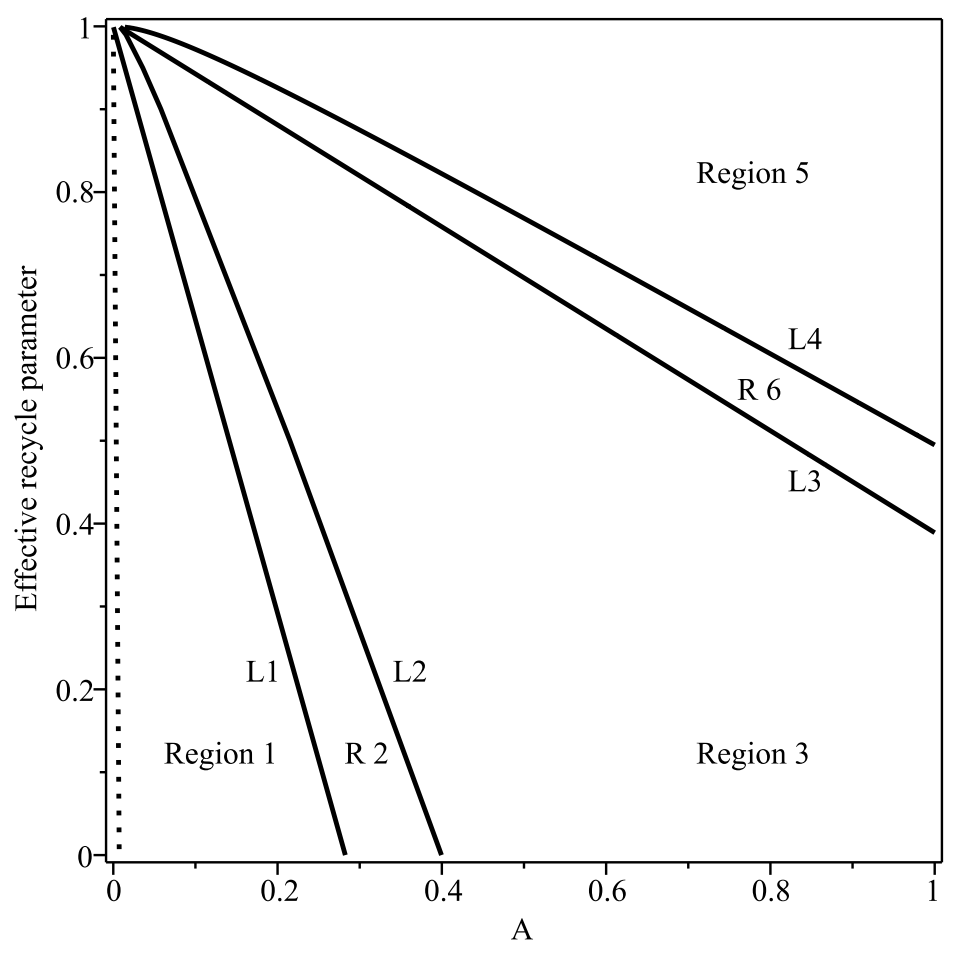

Figure 7: The location of the volatile suspended solids response diagrams in the effective recycle Parameter chemical oxygen demand parameter plane, where $\mathrm{COD}_{\mathrm{in}}^{*}=A \cdot \mathrm{COD}_{\mathrm{in}, \mathrm{old}}^{*}$. The dotted line represent the minimum value $\mathrm{A}=0.0072$.

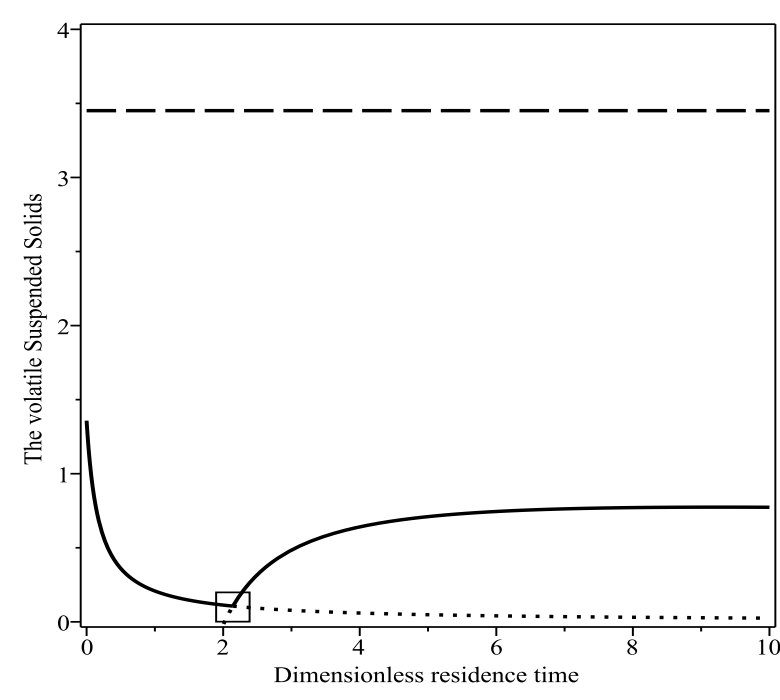

(a) Case one. Parameter values: $R^{*}=0.1$ and $A=0.1$.

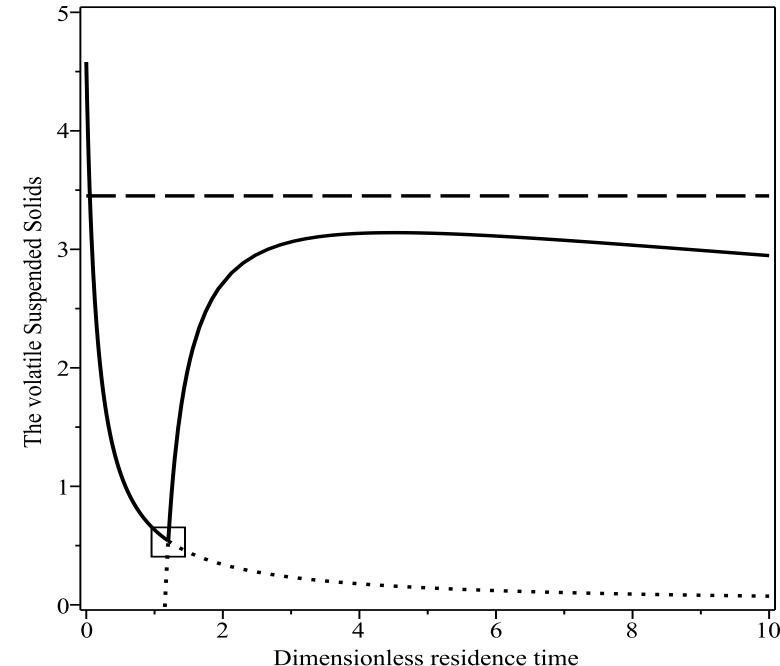

(b) Case two. Parameter values: $R^{*}=0.2$ and $A=0.3$.

Figure 8: Steady-state diagrams showing the volatile suspended solids as a function of the dimensionless residence time $\left(\tau^{*}\right)$. The horizontal dash line denotes the target value of the volatile suspended solids and the horizontal dotted line denotes the asymptotic value. Cases one and two. 